\title{
Actively Targeted Deep Tissue Imaging and Photothermal- Chemo Therapy of Breast Cancer by Antibody-Functionalized Drug-Loaded X-Ray-Responsive Bismuth Sulfide@Mesoporous Silica Core-Shell Nanoparticles
}

\author{
Dr Lihua Li, \\ China-Germany Research Center for Photonic Materials and Device the State Key Laboratory of \\ Luminescent Materials and Devices, and Guangdong Provincial Key Laboratory of Fiber Laser \\ Materials and Applied Techniques, School of Materials Science and Engineering, South China \\ University of Technology, 381 Wushan Road, Guangzhou 510641, China \\ Dr Yao Lu, \\ Guangdong Key Lab of Orthopedic Technology and Implant, Department of Orthopedics \\ Guangzhou General Hospital of Guangzhou Military Command 111 Liuhua Road, Guangzhou, \\ Guangdong 510010, China \\ Dr Chunyan Jiang, \\ China-Germany Research Center for Photonic Materials and Device the State Key Laboratory of \\ Luminescent Materials and Devices, and Guangdong Provincial Key Laboratory of Fiber Laser \\ Materials and Applied Techniques, School of Materials Science and Engineering, South China \\ University of Technology, 381 Wushan Road, Guangzhou 510641, China \\ Dr Ye Zhu, \\ Department of Chemistry and Biochemistry, Stephenson Life Sciences Research Center, \\ University of Oklahoma, Norman, OK 73072, USA \\ Prof Xianfeng Yang, \\ China-Germany Research Center for Photonic Materials and Device the State Key Laboratory of \\ Luminescent Materials and Devices, and Guangdong Provincial Key Laboratory of Fiber Laser \\ Materials and Applied Techniques, School of Materials Science and Engineering, South China \\ University of Technology, 381 Wushan Road, Guangzhou 510641, China

\section{Dr Xiaoming $\mathrm{Hu}$,} \\ Guangdong Key Lab of Orthopedic Technology and Implant, Department of Orthopedics \\ Guangzhou General Hospital of Guangzhou Military Command 111 Liuhua Road, Guangzhou, \\ Guangdong 510010, China \\ Dr Zefeng Lin,
}

Correspondence to: Mingying Peng; Hong Xia; Chuanbin Mao.

L.H.L. and Y.L. contributed equally to this work.

Conflict of Interest

The authors declare no conflict of interest.

Supporting Information

Supporting Information is available from the Wiley Online Library or from the author. 
Guangdong Key Lab of Orthopedic Technology and Implant, Department of Orthopedics Guangzhou General Hospital of Guangzhou Military Command 111 Liuhua Road, Guangzhou, Guangdong 510010, China

\section{Prof Yu Zhang,}

Guangdong Key Lab of Orthopedic Technology and Implant, Department of Orthopedics Guangzhou General Hospital of Guangzhou Military Command 111 Liuhua Road, Guangzhou, Guangdong 510010, China

\section{Prof Mingying Peng,}

China-Germany Research Center for Photonic Materials and Device the State Key Laboratory of Luminescent Materials and Devices, and Guangdong Provincial Key Laboratory of Fiber Laser Materials and Applied Techniques, School of Materials Science and Engineering, South China University of Technology, 381 Wushan Road, Guangzhou 510641, China

Prof Hong Xia, and

Guangdong Key Lab of Orthopedic Technology and Implant, Department of Orthopedics Guangzhou General Hospital of Guangzhou Military Command 111 Liuhua Road, Guangzhou, Guangdong 510010, China

\section{Prof Chuanbin Mao}

Department of Chemistry and Biochemistry, Stephenson Life Sciences Research Center, University of Oklahoma, Norman, OK 73072, USA

School of Materials Science and Engineering, Zhejiang University, Hangzhou, Zhejiang 310027, China

\section{Abstract}

A theranostic platform combining synergistic therapy and real-time imaging attracts enormous attention but still faces great challenges, such as tedious modifications and lack of efficient accumulation in tumor. Here, a novel type of theranostic agent, bismuth sulfide@ mesoporous silica $\left(\mathrm{Bi}_{2} \mathrm{~S}_{3} @ \mathrm{mPS}\right.$ ) core-shell nanoparticles (NPs), for targeted image-guided therapy of human epidermal growth factor receptor-2 (HER-2) positive breast cancer is developed. To generate such NPs, polyvinylpyrrolidone decorated rod-like $\mathrm{Bi}_{2} \mathrm{~S}_{3}$ NPs are chemically encapsulated with a mesoporous silica (mPS) layer and loaded with an anticancer drug, doxorubicin. The resultant NPs are then chemically conjugated with trastuzumab (Tam, a monoclonal antibody targeting HER-2 overexpressed breast cancer cells) to form Tam- $\mathrm{Bi}_{2} \mathrm{~S}_{3} @ \mathrm{mPS}$ NPs. By in vitro and in vivo studies, it is demonstrated that the Tam- $\mathrm{Bi}_{2} \mathrm{~S}_{3} @ \mathrm{mPS}$ bear multiple desired features for cancer theranostics, including good biocompatibility and drug loading ability as well as precise and active tumor targeting and accumulation (with a bismuth content in tumor being $\approx 16$ times that of nontargeted group). They can simultaneously serve both as an excellent contrast enhancement probe (due to the presence of strong X-ray-attenuating bismuth element) for computed tomography deep tissue tumor imaging and as a therapeutic agent to destruct tumors and prevent metastasis by synergistic photothermalchemo therapy. 


\section{Keywords}

active tumor targeting; photothermal-chemo therapy; porous silica; theranostic nanoparticles; Xray computed tomography

\section{Introduction}

Breast cancer is the most common cancer for women in the world. Especially, the human epidermal growth factor receptor 2 (HER-2) is overexpressed in $25 \%$ breast cancer patients and the HER-2 positive tumors are highly malignant, easy to metastasis, resistant to hormone and chemotherapy, and exhibit poor prognosis. ${ }^{[1]}$ To increase the efficiency of diagnosing and treating this type of breast cancer, it is urgent to develop a new method that can achieve both early accurate diagnosis and targeted therapy. Multifunctional theranostic nanoplatforms integrated with diagnostic and therapeutic functions have attracted considerable attention in cancer nanomedicine research. ${ }^{[2]}$ Currently, many studies have adopted passive targeting strategies, based on the enhanced permeability and retention (EPR) effect, to target nanoparticles (NPs) to tumors. ${ }^{[3]}$ However, the passive targeting strategies are still limited by tumor types. ${ }^{[4]}$ Modifying NPs with peptides ${ }^{[5]}$ or antibodies ${ }^{[6,7]}$ has been proposed to effectively solve the above problems because it further enhanced the accumulation in tumor sites. ${ }^{[8]}$ Moreover, integrating multiple types of therapeutic drugs and methods together on the same NPs will significantly enhance the efficacy of cancer therapy.

Many nanotheranostic platforms, which can be excited by magnetism, light, ultrasound, or $\mathrm{X}$-ray, have been established in the past years, including nanomaterials of $\mathrm{Fe}_{3} \mathrm{O}_{4},{ }^{\left[{ }^{[}\right]} \mathrm{Gd}_{2} \mathrm{O}_{3}$, ${ }^{[10]}$ gold, ${ }^{[11]}$ carbon, ${ }^{[12]}$ and semiconductors. ${ }^{[13]}$ Among these nanomaterials, the NPs that can be applied in deep tissue imaging, such as X-ray computed tomography (CT) imaging, are more appealing for clinical use. X-ray-responsive NPs are particularly popular for their high spatial resolution in 3D reconstruction of interested tissues and areas by CT imaging. Bismuth (Bi)-based NPs hold great promise as novel X-ray CT imaging contrast agents due to their high atomic number, great ability in attenuating X-ray, and long residence time. ${ }^{[14]}$ Moreover, $\mathrm{Bi}$ is the earliest reported drug used in clinics and its biocompatibility has been carefully and comprehensively investigated. ${ }^{[15]}$ In addition, the narrow direct bandgap $(\approx 1.3$ $\mathrm{eV}$ ) of bismuth sulfide makes it possible to absorb near infrared (NIR) light to initiate the photothermal cancer therapy. To date, various shapes of bismuth sulfide NPs have been exploited, including spheres ${ }^{[16]}$ and rods ${ }^{[17]}$ for photothermal therapy (PTT) or CT contrast imaging in addition to ternary nanomaterials $\mathrm{Cu}_{3} \mathrm{BiS}_{3} \cdot{ }^{[18]}$ Meanwhile, bismuth sulfide NPs with a wide range of size from 5 to $300 \mathrm{~nm}$ have also been investigated for in vivo CT imaging. ${ }^{[19]}$

Previous reports suggested that $\mathrm{Bi}_{2} \mathrm{~S}_{3}$ NPs can be an ideal nanotheranostic platform. ${ }^{\text {[20] }}$ However, so far, the surface functionalization on $\mathrm{Bi}_{2} \mathrm{~S}_{3}$ NPs has been difficult, limiting the capability of loading drugs on the NPs, and the past studies on $\mathrm{Bi}_{2} \mathrm{~S}_{3} \mathrm{NPs}$ adopted only EPR-based passive tumor targeting, limiting the efficacy of targeted cancer therapy and imaging as well as the early cancer diagnosis. This study was designed to solve these problems. Specifically, we form a mesoporous silica (mPS) shell on the $\mathrm{Bi}_{2} \mathrm{~S}_{3} \mathrm{NPs}$ by a 
modified Stöber method without using a surfactant such as cetyltrimethylammonium bromide and chloride, allowing us not only to conjugate functional molecules (such as an antibody that can target breast cancer along with a polyethylene glycol (PEG) linker to ensure the long circulation and active tumor targeting of the NPs) but also to load the chemotherapeutic drug (doxorubicin, DOX) in the porous shell (Scheme 1).

In our approach, water-soluble polyvinylpyrrolidone (PVP)-decorated $\mathrm{Bi}_{2} \mathrm{~S}_{3} \mathrm{NPs}$ (PVP$\mathrm{Bi}_{2} \mathrm{~S}_{3}$ ) were prepared by a facile hydrothermal method and then coated with a thin PS shell. The resultant NPs, termed $\mathrm{Bi}_{2} \mathrm{~S}_{3} @ \mathrm{mPS}$, can function as an excellent photothermal agent as well as anticancer drug reservoir and also support further modification due to the abundant Si-OH groups on their surface. Trastuzumab (HER-2 monoclonal antibody, Tam), which specifically recognizes the HER-2 receptor on the HER-2 positive SKBR-3 breast cancer cells, was then conjugated to the as-synthesized $\mathrm{Bi}_{2} \mathrm{~S}_{3} @$ mPS through a PEGbased linker (NHS-PEG-Mal, for improving in vivo biocompatibility and stability of the NPs and linking with the antibody). The resultant NPs, termed Tam- $\mathrm{Bi}_{2} \mathrm{~S}_{3} @ \mathrm{mPS}$, were then loaded with an anticancer drug, DOX, to form Tam- $\mathrm{Bi}_{2} \mathrm{~S}_{3} @ \mathrm{mPS} / \mathrm{DOX}$ NPs due to the presence of a PS shell. The final Tam- $\mathrm{Bi}_{2} \mathrm{~S}_{3} @ \mathrm{mPS} / \mathrm{DOX}$ NPs were intravenously (i.v.) injected into tumorbearing mice model (generated by injection of SKBR-3 breast cancer cells) and then efficiently transported to the tumor site due to the active targeting of Tam. The NPs then function as CT contrast enhancement agents for the detection of the tumor sites for cancer diagnosis. In the meantime, the NPs will destruct the tumor by a combination of photothermal and chemotherapeutic therapy (i.e., photothermal-chemo therapy). The PTT arises from the photothermal effect of the $\mathrm{Bi}_{2} \mathrm{~S}_{3}$ NPs in response to $808 \mathrm{~nm}$ NIR laser irradiation. The chemotherapy results from the DOX released from the NPs. The synergistic photothermal and chemotherapeutic effect of the Tam- $\mathrm{Bi}_{2} \mathrm{~S}_{3} @ \mathrm{mPS} / \mathrm{DOX}$ NPs effectively destructed the tumor cells without tumor recurrence. Thus, Tam-Bi $\mathrm{S}_{3} @ \mathrm{mPS} / \mathrm{DOX}$ NPs can serve as an effective tumor-targeting platform that can simultaneously achieve actively targeted cancer imaging/diagnosis (by CT) and photothermal-chemo therapy.

\section{Results and Discussion}

\subsection{Design, Fabrication, and Characterization of $\mathrm{Tam}-\mathrm{Bi}_{2} \mathrm{~S}_{3} @ \mathrm{mPS}$}

The hydrophilic PVP-decorated $\mathrm{Bi}_{2} \mathrm{~S}_{3}\left(\mathrm{PVP}-\mathrm{Bi}_{2} \mathrm{~S}_{3}\right)$ NPs were first synthesized by a facile hydrothermal method. X-ray diffraction (XRD) was employed to investigate the composition and purity of the PVP-Bi $\mathrm{S}_{3}$ NPs. All the peaks in the XRD pattern (Figure S1, Supporting Information) could be well indexed to the orthorhombic $\mathrm{Bi}_{2} \mathrm{~S}_{3}$ crystal (JCPDS No. 652431). Silica was used to coat the NPs because it is biocompatible and can facilitate further antibody modification for clinical application. ${ }^{[21]}$ Moreover, when silica was porous, it can load drug due to the high specific surface area and large pore volume in addition to the wellestablished surface modification chemistry. ${ }^{[22]}$ Hence, we turned to a modified Stöber procedure ${ }^{[23]}$ to coat a porous layer on the PVP- $\mathrm{Bi}_{2} \mathrm{~S}_{3} \mathrm{NPs}$ (Figure 1a). Excitingly, during the silica-coating process, an mPS layer appeared on the NPs (Figure 1e,f). The mPS layer was formed because PVP molecules originally trapped in the NPs were dispersed into the silica shell during the silica-coating process. Hence, the mPS shell structure was obtained after the PVP molecules were washed away from the NPs finally. ${ }^{[24]}$ 
Figure 1b,c shows the representative transmission electron microscopy (TEM) and highresolution transmission electron microscopy (HRTEM) images of PVP- $\mathrm{Bi}_{2} \mathrm{~S}_{3}$. The PVP$\mathrm{Bi}_{2} \mathrm{~S}_{3} \mathrm{NPs}$ are rod-like with a diameter of about $26 \mathrm{~nm}$ and a length of up to $100 \mathrm{~nm}$. The interplanar crystal spacing is $\approx 0.56 \mathrm{~nm}$ (Figure 1c), which is consistent with the lattice spacing of the (200) plane of $\mathrm{Bi}_{2} \mathrm{~S}_{3}$. This result was further confirmed by selected area electron diffraction (SAED) (Figure 1d). After PS coating, $\mathrm{Bi}_{2} \mathrm{~S}_{3} @ \mathrm{mPS}$ NPs have a welldefined rod-like structure of around $130 \mathrm{~nm}$ in length and $60 \mathrm{~nm}$ in width (Figure 1e,f). The high-angle annular dark-field scanning TEM (HAADFSTEM) elemental mapping images confirmed the distribution of $\mathrm{Bi}, \mathrm{S}, \mathrm{Si}$, and $\mathrm{O}$ elements, clearly confirming the presence of $\mathrm{Bi}_{2} \mathrm{~S}_{3}$ cores and mPS shells. Nitrogen adsorption-desorption isotherm was employed to investigate the porous structure, the results (Figure 1g,h) confirmed that the $\mathrm{Bi}_{2} \mathrm{~S}_{3} @ \mathrm{mPS}$ possessed a higher specific surface area $\left(126.383 \mathrm{~cm}^{2} \mathrm{~g}^{-1}\right)$ and a larger pore volume $(0.348$ $\mathrm{cm}^{3} \mathrm{~g}^{-1}$ ). The average pore size was calculated to be $6.48 \mathrm{~nm}$. After coated with $\mathrm{mPS}$, the NPs zeta potential changed from neutral to $-25 \mathrm{mV}$ (Figure S2, Supporting Information).

To improve the in vivo behavior including reduced accumulation in the reticuloendothelial system and enhanced active targeting effect, the $\mathrm{Bi}_{2} \mathrm{~S}_{3} @ \mathrm{mPS}$ was further modified with HER-2 antibody Tam through a PEG linker. First, the $\mathrm{Bi}_{2} \mathrm{~S}_{3} @$ mPS NPs reacted with (3aminopropyl) triethoxysilane (APTES) for $48 \mathrm{~h}$ in ethanol to form NPs terminated with an amino group. Then the resultant $\mathrm{Bi}_{2} \mathrm{~S}_{3} @$ mPS-NH $\mathrm{N}_{2}$ reacted with NHS-PEG-Mal via Michael addition reaction ${ }^{[25]}$ to form $\mathrm{Bi}_{2} \mathrm{~S}_{3} @$ mPS-PEG-Mal NPs. The activated $\mathrm{Bi}_{2} \mathrm{~S}_{3} @$ mPS-PEGMal NPs were then covalently coupled to thiolated Tam (SH-Tam) through thiol-maleimide linkages. To further prove the successful surface modification, the absorption spectrum and Fourier transform infrared spectroscopy (FTIR) spectrum were collected. As shown in Figure 2a, the PVP- $\mathrm{Bi}_{2} \mathrm{~S}_{3}$ exhibited a broad absorption from 400 to $900 \mathrm{~nm}$. After the NPs were coated with silica, an enhanced absorption band appeared in the whole spectrum region due to the abundant $-\mathrm{OH}$ in silica (Figure 2a). When conjugated with Tam, the samples presented a new strong absorption band in 250-300 nm, which was in accordance with the protein peak in Tam (Figure 2a). Later, the FTIR was employed to investigate the successful conjugation of Tam (Figure 2b). The peak that appeared at $3428 \mathrm{~cm}^{-1}$ corresponds to the -OH groups in $\mathrm{Bi}_{2} \mathrm{~S}_{3} @ \mathrm{mPS}$ and Tam- $\mathrm{Bi}_{2} \mathrm{~S}_{3} @ \mathrm{mPS}$ samples. The vibration that showed up in $1422 \mathrm{~cm}^{-1}$ could be assigned to $\mathrm{COO}^{-}$in Tam- $\mathrm{Bi}_{2} \mathrm{~S}_{3} @ \mathrm{mPS}$. The new peaks in 1102 and $539 \mathrm{~cm}^{-1}$ correspond to the vibration of $-\mathrm{S}-\mathrm{R}$ - group, which further confirmed the successful conjugation of Tam with $\mathrm{Bi}_{2} \mathrm{~S}_{3} @ \mathrm{mPS}-\mathrm{NH}_{2}$. Furthermore, the zeta potential of $\mathrm{Bi}_{2} \mathrm{~S}_{3} @ \mathrm{mPS}-\mathrm{NH}_{2}$ was $20 \mathrm{mV}$ and the final Tam- $\mathrm{Bi}_{2} \mathrm{~S}_{3} @ \mathrm{mPS}$ was nearly neutral (Figure S2, Supporting Information), which was in agreement with the FTIR results.

\subsection{Drug Loading, Releasing, and Photothermal Efficiency}

It is worthwhile to note that the thin mPS shell ensures that the $\mathrm{Bi}_{2} \mathrm{~S}_{3} @ \mathrm{mPS}$ NPs work as a good drug carrier while maintaining the high photothermal conversion (PTC) efficiency of $\mathrm{Bi}_{2} \mathrm{~S}_{3}$ NPs. To prove this hypothesis, drug-loading efficiency and photothermal effect were tested on the NPs. First, the common chemotherapeutic drug, doxorubicin (DOX), used in breast cancer therapy was selected as a model drug. ${ }^{[26]}$ It was loaded with $\mathrm{Bi}_{2} \mathrm{~S}_{3} @$ mPS by mixing the NPs and the drug under constant stirring for $24 \mathrm{~h}$. The loading capacity was found to be as high as $60.85 \mathrm{mg} / 100 \mathrm{mg}$ due to the large pore size and surface area of 
$\mathrm{Bi}_{2} \mathrm{~S}_{3} @ \mathrm{mPS}$ (Figure 2c). The drug release rate was also tested in an acidic or neutral environment. The DOX showed a quick release at $\mathrm{pH} 5.0$ but a very slow release at $\mathrm{pH} 7.4$ (Figure 2d). Moreover, when the temperature rose from room temperature to $37^{\circ} \mathrm{C}$, a faster release of DOX from the $\mathrm{Bi}_{2} \mathrm{~S}_{3} @ \mathrm{mPS}$ occurred in neutral or acidic phosphate buffered solution (PBS) solution. This phenomenon suggests that our NPs hold great promise for selective drug release in tumor in vivo because the tumor microenvironment was acidic $(\mathrm{pH}$ $4-5$ in lysosomes and $\mathrm{pH} 5-6$ in endosomes). ${ }^{[27]}$

Although the PVP-Bi ${ }_{2} \mathrm{~S}_{3}$ and $\mathrm{Bi}_{2} \mathrm{~S}_{3} @ \mathrm{mPS}$ have broad absorption peaks in the NIR region (Figure 2a), the silica coating may hinder the photothermal effect of the NPs. Hence, we compared the photothermal properties between PVP- $\mathrm{Bi}_{2} \mathrm{~S}_{3}$ and $\mathrm{Bi}_{2} \mathrm{~S}_{3} @ \mathrm{mPS}$. The photothermal properties of two samples were tested under $808 \mathrm{~nm}$ NIR laser $\left(1 \mathrm{~W} \mathrm{~cm}^{-2}\right)$ with pure water as a control. Both the PVP-Bi ${ }_{2} \mathrm{~S}_{3}$ and $\mathrm{Bi}_{2} \mathrm{~S}_{3} @$ mPS NPs showed a thermal

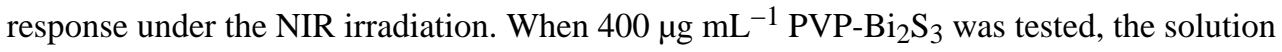
could reach up to $65{ }^{\circ} \mathrm{C}$ under 10 min continuous irradiation $\left(808 \mathrm{~nm}, 1 \mathrm{~W} \mathrm{~cm}^{-2}\right)$. However, the temperature of pure water could only reach $28^{\circ} \mathrm{C}$. Luckily, after coated with mPS, the resultant $\mathrm{Bi}_{2} \mathrm{~S}_{3} @ \mathrm{mPS}$ (with the same concentration of $\mathrm{Bi}$ as $\mathrm{PVP}-\mathrm{Bi}_{2} \mathrm{~S}_{3}$ ) solution also could reach as high as $\left.60^{\circ} \mathrm{C}(808 \mathrm{~nm}, 1 \mathrm{~W} \mathrm{~cm})^{-2}\right)$. According to these data, the PTC efficiencies of $\mathrm{PVP}-\mathrm{Bi}_{2} \mathrm{~S}_{3}$ and $\mathrm{Bi}_{2} \mathrm{~S}_{3} @ \mathrm{mPS}$ were calculated to be $\approx 32.46 \%$ and $29.53 \%$, respectively (Figure 3b,d; the detailed calculation method was presented in the Supporting Information). The excellent NIR to thermal conversion efficiency of $\mathrm{Bi}_{2} \mathrm{~S}_{3} @ \mathrm{mPS}$ NPs promises them to be an excellent photothermal nanoagent.

As supported by the high PTC of $\mathrm{Bi}_{2} \mathrm{~S}_{3} @ \mathrm{mPS}$, the photothermal effect of $\mathrm{Bi}_{2} \mathrm{~S}_{3} @ \mathrm{mPS}$ and targeted Tam- $\mathrm{Bi}_{2} \mathrm{~S}_{3} @ \mathrm{mPS}$ was also investigated in vivo (Figure 3c). After i.v. injection of the solution of $\mathrm{NaCl}, \mathrm{Bi}_{2} \mathrm{~S}_{3} @ \mathrm{mPS}$, and Tam- $\mathrm{Bi}_{2} \mathrm{~S}_{3} @ \mathrm{mPS}$ NPs, the hyperthermia effect in the tumor site was carefully recorded by an IR camera when a NIR light was irradiating the tumor site. In $\mathrm{Bi}_{2} \mathrm{~S}_{3} @ \mathrm{PS}$ group, the temperature in tumor site was about $40{ }^{\circ} \mathrm{C}$ after $10 \mathrm{~min}$ irradiation ( $808 \mathrm{~nm}, 1 \mathrm{~W} \mathrm{~cm}^{-2}$ ). It was higher than the temperature in the control group due to the EPR effect, but still slightly lower than the reported minimum temperature $\left(41^{\circ} \mathrm{C}\right)^{[28]}$ needed to destruct tumors by hyperthermia. Impressively, the temperature in Tam-

$\mathrm{Bi}_{2} \mathrm{~S}_{3} @ \mathrm{mPS}$ group (up to $46^{\circ} \mathrm{C}$ ) was above the minimum hyperthermia temperature due to their good targeting to the tumor sites.

\subsection{Cell Viability}

The in vitro biocompatibility of $\mathrm{Bi}_{2} \mathrm{~S}_{3} @ \mathrm{mPS}, \mathrm{Tam}_{-} \mathrm{Bi}_{2} \mathrm{~S}_{3} @ \mathrm{mPS}$, and DOX was carried out on SKBR-3 cells by a standard 3-4,5-dimethylthiazol-2-yl-2,5-diphenyltetrazolium bromide (MTT) method. As shown in Figure 4a, there was a negligible effect on the cells even for the $\mathrm{Bi}_{2} \mathrm{~S}_{3} @ \mathrm{mPS}$ with a concentration of up to $400 \mu \mathrm{g} \mathrm{mL}-1$, which verified its good biocompatibility. While for Tam-Bi ${ }_{2} \mathrm{~S}_{3} @ \mathrm{mPS}\left(400 \mu \mathrm{g} \mathrm{mL} \mathrm{m}^{-1}\right)$, the survival rate was slightly lower than $80 \%$ because of the Tam toxicity toward SKBR-3 cells. With the decrease in the concentrations of Tam- $\mathrm{Bi}_{2} \mathrm{~S}_{3} @ \mathrm{mPS}$ NPs, the NPs showed low cytotoxicity on SKBR-3 cells. Considering the cell biocompatibility and photothermal effect, $200 \mu \mathrm{g} \mathrm{mL} L^{-1}$ was selected as the concentration of Tam- $\mathrm{Bi}_{2} \mathrm{~S}_{3} @ \mathrm{mPS}$ NPs used for the following experiments. Under $1 \mathrm{~W} \mathrm{~cm}^{-2} \mathrm{NIR}$ irradiation, cell viabilities decreased when Tam and/or DOX was on 
the NPs (Figure 4b). In addition, due to the high toxicity of DOX in vitro, the DOX-loaded carriers showed severe toxicity to cancer cells in vitro. Especially in Tam- $\mathrm{Bi}_{2} \mathrm{~S}_{3} @$ $\mathrm{mPS} / \mathrm{DOX}+\mathrm{NIR}$ group, the cell viability was lower than $15 \%$ due to the synergistic effect of photothermal-chemo therapy (Figure 4b).

The hemolytic properties of the NPs (Figure 4c) were tested to understand the response of blood to the intravenous NPs administration in vivo. No visual red color occurred in the $\mathrm{Bi}_{2} \mathrm{~S}_{3} @ \mathrm{mPS}$ group with a gradient concentration ranging from 12.5 to $400 \mu \mathrm{g} \mathrm{mL} \mathrm{m}^{-1}$ and PBS group, illustrating the good blood biocompatibility of the as-synthesized NPs. The red color in pure water group was attributed to the hemoglobin from erythrocyte.

Cell viability was further investigated by fluorescence live/dead staining. There were negligible dead cells (red cells) in the control, NIR, and $\mathrm{Bi}_{2} \mathrm{~S}_{3} @ \mathrm{mPS}$ NPs treatment groups. In contrast, all of the cells in Tam- $\mathrm{Bi}_{2} \mathrm{~S}_{3} @ \mathrm{mPS} / \mathrm{DOX}+\mathrm{NIR}$ group were dead with a round shape (red color), which was consistent with the MTT results. These results illustrated an enhanced combined photothermal-chemo effect for in vitro cancer therapy.

\subsection{In Vitro Cancer Cell Targeting Effect}

SKBR-3 breast cancer cells overexpress HER-2. HER-2 is associated with enhanced cell proliferation and survival, increased disease progression risk, and decreased overall survival rate. Tam is a famous monoclonal antibody directly against the HER-2 and has been clinically recommended for HER-2 positive cancers including breast cancer and gastric cancer. ${ }^{[29]}$ Therefore, it has been selected for in vitro and in vivo HER-2 positive breast cancer targeting in this study. The FITC-labeled NPs were investigated by fluorescence microscope and flow cytometry. After being cocultured with FITC-labeled NPs (Tam$\mathrm{Bi}_{2} \mathrm{~S}_{3} @ \mathrm{mPS}$ NPs or $\mathrm{Bi}_{2} \mathrm{~S}_{3} @ \mathrm{mPS}$ NPs) or free FITC in dark for $24 \mathrm{~h}$, a rigorous washing protocol was carried out to ensure that all noninternalized particles were removed from the cell surface prior to fluorescence imaging and flow cytometry analysis. The SKBR-3 cells cocultured with Tam-Bi $\mathrm{S}_{2} @ \mathrm{mPS}$-FITC NPs presented strong and well-proportioned green fluorescence, whereas a very weak fluorescence was observed in $\mathrm{Bi}_{2} \mathrm{~S}_{3} @$ mPS-FITC under the same condition (Figure 5a). These results confirmed the cancer cell targeting capability of Tam-modified NP groups. The flow cytometry results further indicated the targeted effect (Figure 5b). Namely, after incubation with different groups for $24 \mathrm{~h}$, the mean fluorescence intensity of Tam- $\mathrm{Bi}_{2} \mathrm{~S}_{3} @ \mathrm{mPS}$ group also showed the most distinguished enhancement (Figure 5c).

To further prove that Tam- $\mathrm{Bi}_{2} \mathrm{~S}_{3} @ \mathrm{mPS}$ NPs could selectively target HER-2 positive cancer cells, we examined the interaction of FITC-labeled Tam-Bi $2 \mathrm{~S}_{3} @$ mPS NPs with HER-2 negative MCF-7 cells using the fluorescence microscopy. We found that MCF-7 cells incubated with $\mathrm{Bi}_{2} \mathrm{~S}_{3} @ \mathrm{mPS}$-FITC or Tam-Bi $\mathrm{S}_{3} @$ mPS-FITC showed similar but very weak fluorescence from FITC (Figure S5, Supporting Information). This result implies that Tam- $\mathrm{Bi}_{2} \mathrm{~S}_{3} @ \mathrm{mPS}$ NPs could not target HER-2 negative cancer cells, further confirming the capability of Tam-Bi $\mathrm{S}_{3} @ \mathrm{mPS}$ in targeting HER-2 positive cancer cells. 


\subsection{In Vivo Targeted Imaging}

The in vitro results encouraged us to further investigate Tam- $\mathrm{Bi}_{2} \mathrm{~S}_{3} @ \mathrm{mPS}$ in vivo. Bismuthbased nanomaterials such as $\mathrm{Bi}_{2} \mathrm{~S}_{3}{ }^{[30]}$ and $\mathrm{Bi}_{2} \mathrm{Se}_{3}{ }^{[31]}$ are proved to be excellent candidates in CT contrast imaging agents due to their enhanced X-ray attenuation coefficient. We first investigated and compared the Hounsfield units (HU) values of Tam- $\mathrm{Bi}_{2} \mathrm{~S}_{3} @ \mathrm{mPS}$ and iobitridol (the thirdgeneration CT contrast agent as a gold standard) with different concentrations. The CT signal was found to be gradually enhanced with the increase of Tam$\mathrm{Bi}_{2} \mathrm{~S}_{3} @ \mathrm{mPS}$ concentration (Figure 6a). Eventually, the Tam-Bi $\mathrm{S}_{3} @ \mathrm{mPS}$ NPs exhibited even a higher CT value per unit (42.58) with mass concentration than iobitridol (26.91) and iopromide (16.38) and previously reported $\mathrm{Bi}_{2} \mathrm{~S}_{3}$ materials. ${ }^{[16,30,32]}$ Moreover, we examined the noble metal gold nanorods under the same condition, and found the slope of the CT contrast value versus the concentration is $\approx 31.26$ for the gold nanorods (Figure S6, Supporting Information), which is lower than that for the Tam-Bi $2 \mathrm{~S}_{3} @ \mathrm{mPS}$ (42.58). Considering the strong enhancement of X-ray attenuation, we assessed the targeting and CT imaging effect of Tam-Bi $\mathrm{S}_{3} @ \mathrm{mPS}$ NPs at 2, 6, and $24 \mathrm{~h}$ after i.v. injection of NPs into tumor-bearing mice. As shown in Figure 6b, the tumor site exhibited an enhanced imaging contrast after i.v. injection of Tam- $\mathrm{Bi}_{2} \mathrm{~S}_{3} @ \mathrm{mPS}$ compared to the peritumoral tissue. Such a high contrast will be helpful for precise cancer diagnosis and resection in clinical application. Notably, the CT contrast image was still clear $24 \mathrm{~h}$ after i.v. injection, suggesting the excellent and stable accumulation of NPs in tumor site. These results indicate that the special rod-like structure of the Tam- $\mathrm{Bi}_{2} \mathrm{~S}_{3} @ \mathrm{mPS}$ NPs has advantages over the spherical NPs in interaction with target cells and prevention from extravasation, as illustrated by Mitragotri et al. ${ }^{[33]}$ Meanwhile, with the increase in time, the spleen CT intensity was gradually decreased while there was only ignorable reduction in the CT intensity in the tumor site. It is worthwhile to note that the tumor profile was clearly revealed by CT imaging due to the rich blood vessels in this area although the NPs can hardly reach the inner part of the tumor site because of the heterogeneous and leaky distribution of vascular patterns. ${ }^{[34]}$ We also compared the CT intensity of the main organs and tumors in the untargeting (i.e., non-Tam-modified) group with the targeting (i.e., Tam-modified) group (Figure 6). We found that the tumor site had almost no enhanced imaging in the untargeting group. Overall, as Figure 6b illustrates for in vivo imaging, 10 mg mL ${ }^{-1}$ Tam- $\mathrm{Bi}_{2} \mathrm{~S}_{3} @ \mathrm{mPS}$ shows enough CT contrast for imaging because Tam- $\mathrm{Bi}_{2} \mathrm{~S}_{3} @ \mathrm{mPS}$ can target the tumor and thus accumulate within the tumor sites.

To further prove the targeting effect of Tam-modified group, the tissue distribution of bismuth was also carefully quantified by ICP-MS (Figure S3, Supporting Information) in tumor-bearing mice $24 \mathrm{~h}$ after intravenous injection. In $\mathrm{Bi}_{2} \mathrm{~S}_{3} @ \mathrm{mPS}$ group, average splenic uptake was determined to be $151.3 \mathrm{\mu g} \mathrm{g}^{-1}$, while the uptake in liver, lung, and tumor site was 92.9, 117.5, and $12.44 \mu \mathrm{g} \mathrm{g}^{-1}$, respectively. After modified with Tam, a significantly increased bismuth content $\left(195.2 \mu \mathrm{g} \mathrm{g}^{-1}\right)$ was found in the tumor and this value was about 16 times that of the nontargeting $\mathrm{Bi}_{2} \mathrm{~S}_{3} @$ mPS group. In contrast, the bismuth in the peritumoral tissues was not so high in the Tam-modified group (Figure S2, Supporting Information), indicating the efficient targeting effect. It's worth noting that only little bismuth was found in the lung site in the Tam- $\mathrm{Bi}_{2} \mathrm{~S}_{3} @ \mathrm{mPS}$ group, probably because PEG and Tam modification on the NPs could avoid nonspecific aggregation and decrease the 
accumulation in lung. ${ }^{[35]}$ Therefore, the Tam-modified NPs have a great potential in serving as a tumor-targeting CT contrast enhancement agent for cancer diagnosis.

\subsection{In Vivo PTT and Chemotherapy Effect}

The efficient $\mathrm{Bi}_{2} \mathrm{~S}_{3}$ accumulation in the tumor site is beneficial to cancer diagnosis and therapy. The targeted photothermalchemo effect of Tam-Bi $\mathrm{S}_{2} @ \mathrm{mPS} / \mathrm{DOX}$ was further investigated in vivo, which lays foundation for future anticancer application. As shown in Figure $7 \mathrm{a}, \mathrm{b}$, visual images of tumors in different groups on day 14 post treatment can be seen. In the Tam- $\mathrm{Bi}_{2} \mathrm{~S}_{3} @ \mathrm{mPS}+\mathrm{NIR}$ group, though the tumor was inhibited by the hyperthermia effect during the therapy period, there were still some residual tumors after 14 d. Excitingly, the tumor volume in Tam- $\mathrm{Bi}_{2} \mathrm{~S}_{3} @ \mathrm{mPS} / \mathrm{DOX}+\mathrm{NIR}$ group became reduced significantly and the tumor even disappeared. A more detailed dynamic change in the tumor volume and body weight was recorded. As shown in Figure 7c, the tumors grew rapidly in the control, DOX, and Tam- $\mathrm{Bi}_{2} \mathrm{~S}_{3} @ \mathrm{mPS} / \mathrm{DOX}$ groups. In the nontargeting $\mathrm{Bi}_{2} \mathrm{~S}_{3} @ \mathrm{mPS} / \mathrm{DOX}+\mathrm{NIR}$ or targeting Tam-Bi $\mathrm{S}_{3} @ \mathrm{mPS}+\mathrm{NIR}$ groups, tumor size was not completely suppressed and still presented a growth trend due to the insufficient hyperthermia (for the lack of NP accumulation although with DOX) or lack of DOX toxicity at the tumor site. In contrast, the tumors in Tam- $\mathrm{Bi}_{2} \mathrm{~S}_{3} @ \mathrm{mPS} / \mathrm{DOX}+\mathrm{NIR}$ group became smaller and even disappeared over time, illustrating the excellent precise photothermal-chemo therapy. As Figure $7 \mathrm{~d}$ shows, the body weight of the mice during the treatment always lies between 18 and $20 \mathrm{~g}$ for different treatment groups, suggesting that the treatment did not obviously influence the body weight. In addition, the histological changes of the tumors were also studied (Figure 7e). The histological staining of tumor sites in the control, DOX+NIR, and Tam- $\mathrm{Bi}_{2} \mathrm{~S}_{3} @ \mathrm{mPS} / \mathrm{DOX}$ groups showed typical pathological characteristics of breast cacner and clear vascular structure, demonstrating negliable effect when only NIR light (i.e., without NPs) or Tam- $\mathrm{Bi}_{2} \mathrm{~S}_{3} @ \mathrm{mPS} / \mathrm{DOX}$ (i.e., without NIR irradiaiton) was used to treat tumor. Tam- $\mathrm{Bi}_{2} \mathrm{~S}_{3}+\mathrm{NIR}$ group showed that some tumor tissues were damaged but the recurrence of tumor was also found in this group. These results were consistent with the results on the tumor volume change (Figure 7c). For Tam- $\mathrm{Bi}_{2} \mathrm{~S}_{3} @ \mathrm{mPS} / \mathrm{DOX}+\mathrm{NIR}$ group, severe damage at the tumor site was identified, such as swelling cell nucleus, cell vacuoles, ambiguous intercellular gap as well as vague, and atrophy tomor structure. The hematoxylin and eosin (H\&E) staining of tumor tissues demonstrated that NIR illuminated DOX-loaded nanocomposites caused more severe tumor cell damage and irreversible necrosis when compared with the other groups. Therefore, based on the excellent drug delivery ability and photothermal conversion effect, the NPs that include both the phototheral bismuth sulfide and DOX can also work as an efficient anticancer nanoagent in clinics.

\subsection{H\&E Staining}

To further investigate the in vivo biocompatibility and therapy effect, the H\&E stained images of the heart, liver, spleen, lung, kidney, intestine, brain, and peritumor muscle are collected (Figure S4, Supporting Information). There was no tissue damage or adverse effect in the Tam- $\mathrm{Bi}_{2} \mathrm{~S}_{3} @ \mathrm{mPS} / \mathrm{DOX}+\mathrm{NIR}$ treatment group. Namely, the glomerulus structure was clear and complete in the kindney section of the treatment group, hepatocytes were normal, and no pulmonary fibrosis or congestion was found, indicating the good biocompatiblity of these NPs. However, in control groups, some SKBR-3 tumor cells appeared in peritumor 
muscle and the tumor profile became vague, indicating the metabolism of the tumors in these groups. As expected, the histopathologic characteristics in the peritumoral muscle of Tam-Bi $\mathrm{S}_{3} @ \mathrm{mPS}+\mathrm{NIR}$ and Tam-Bi $\mathrm{S}_{3} @ \mathrm{mPS} / \mathrm{DOX}+\mathrm{NIR}$ groups were completely normal due to targeting capability of the Tam on the NPs.

\section{Conclusion}

In conclusion, successful cancer-targeting $\mathrm{Bi}_{2} \mathrm{~S}_{3}$ theranostic NPs were established. The multifunctional Tam- $\mathrm{Bi}_{2} \mathrm{~S}_{3} @ \mathrm{mPS}$ nanoplatform shows excellent biocompatibility, cancertargeted bioimaging, as well as synergistic photothermal/chemotherapeutic therapy. Notably, thin PS coatings were formed on the PVP- $\mathrm{Bi}_{2} \mathrm{~S}_{3}$ precursors, which guarantee the drug delivery effect but still maintaining good photothermal conversion efficiency. Meanwhile, after being modified with Tam, the nanocomposites show an effectively enhanced cancertargeting effect. In addition, more than 20\% Tam- $\mathrm{Bi}_{2} \mathrm{~S}_{3} @ \mathrm{mPS}$ nanocomposites were gathered in tumor site for in vivo imaging and therapy, suggesting that the NPs can work as a precise bomb for tumor tracing and synergistic photothermal-chemo therapy. More importantly, the simultaneous photothermal-chemo therapy based on Tam-

$\mathrm{Bi}_{2} \mathrm{~S}_{3} @ \mathrm{mPS} / \mathrm{DOX}$ under NIR laser could efficiently kill the tumor cells and prevent cancer metastasis. Hence, the Tam- $\mathrm{Bi}_{2} \mathrm{~S}_{3} @ \mathrm{mPS} / \mathrm{DOX}$ NPs can provide significant contrast enhancement for CT imaging and cancer diagnosis as well as strengthen tumor ablation efficiency, enabling their bright future for clinical cancer diagnosis and therapy.

\section{Experimental Section}

\section{Preparation of $\mathrm{PVP}-\mathrm{Bi}_{2} \mathrm{~S}_{3} \mathrm{NPs}$}

The PVP-Bi ${ }_{2} \mathrm{~S}_{3}$ NPs were prepared by a facile hydrothermal method. Briefly, $0.498 \mathrm{~g}$ bismuth nitrate pentahydrate was added to $70 \mathrm{~mL}$ ethylene glycol solution with constant stirring. After vigorous stirring for $30 \mathrm{~min}, 0.5 \mathrm{~g} \mathrm{PVP}$ was added to the solution and stirred for 30 min. $2 \mathrm{~mL}$ deionized $\mathrm{H}_{2} \mathrm{O}$ containing $\mathrm{Na}_{2} \mathrm{~S} \cdot 9 \mathrm{H}_{2} \mathrm{O}(0.36 \mathrm{~g})$ was added to the mixture dropwise and the mixture turned to black quickly. The solution was transferred into a 100 $\mathrm{mL}$ Teflon-lined autoclave, sealed, and heated up to $180^{\circ} \mathrm{C}$ for $2 \mathrm{~h}$ in an electric furnace. Afterward, the autoclave was cooled naturally to room temperature, and the final products were collected by centrifugation and washed three times with ethanol and distilled water, respectively, to remove any possible remnants.

\section{Preparation of $\mathrm{Bi}_{2} \mathrm{~S}_{3} @ \mathrm{mPS}$ and $\mathrm{Bi}_{2} \mathrm{~S}_{3} @ \mathrm{mPS}-\mathrm{NH}_{2}$}

In a typical procedure, $20 \mathrm{mg}$ PVP-Bi ${ }_{2} \mathrm{~S}_{3} \mathrm{NPs}$ were dissolved in $65 \mathrm{~mL}$ ethanol upon ultrasonication for $30 \mathrm{~min}$. Subsequently, $2.8 \mathrm{~mL}$ concentrated ammonia aqueous solution (28\%) was added dropwise and stirred for $30 \mathrm{~min}$ at room temperature. Then $65 \mu \mathrm{L}$ tetraethoxysilane was dissolved in $6.5 \mathrm{~mL}$ ethanol and added dropwise to the solution at a rate of $0.5 \mathrm{~mL} \mathrm{~min}^{-1}$ under vigorous stirring. After stirring for $6 \mathrm{~h}$ at room temperature, the products were separated by centrifugation and washed in sequence with ethanol and water. The final products were denoted as $\mathrm{Bi}_{2} \mathrm{~S}_{3} @ \mathrm{mPS}$. For amino group modification, $20 \mathrm{~mL}$ (2 $\left.\mathrm{mg} \mathrm{mL} \mathrm{m}^{-1}\right) \mathrm{Bi}_{2} \mathrm{~S}_{3} @ \mathrm{mPS}$ in absolute ethanol was allowed to react with APTES $(1 \mathrm{~mL})$ at room temperature for $48 \mathrm{~h}$ to form $\mathrm{Bi}_{2} \mathrm{~S}_{3} @ \mathrm{mPS}-\mathrm{NH}_{2}$. The final sample was again washed 
with ethanol three times to get rid of free APTES. The concentration of $\mathrm{NH}_{2}$ groups (nmol $\mathrm{mL}^{-1}$ ) was measured with a Kaiser test kit.

\section{Characterization}

Optical absorption spectra of the samples were measured with a spectrophotometer (Perkin Elmer, USA) working in a spectral range from 200 to $1000 \mathrm{~nm}$. The crystalline structure, size, and shape of the nanoparticles were observed by XRD and HRTEM. XRD was measured with a Siemens Kristalloflex 810 D-500 X-ray diffractometer (Karlsruhe, Germany) under an operating mode of $40 \mathrm{kV}$ and $30 \mathrm{~mA}$, with $\lambda=1.5406 \AA$ radiation. $\mathrm{Bi}_{2} \mathrm{~S}_{3}$ NPs in solution were placed onto holey carbon-covered copper grids for HRTEM observation. The HRTEM images, HAADF-STEM image and element mapping were obtained from the particles with a Hitachi 2100 electron microscope with an accelerating voltage of $210 \mathrm{kV}$. FTIR spectra were measured on a PerkinElmer 580B IR spectrophotometer using the $\mathrm{KBr}$ pellet technique. $\mathrm{N}_{2}$ adsorption/desorption isotherms were obtained on a Micromeritics ASAP Tristar II 3020 apparatus. Zeta potential measurements were determined with the Zetasizer Nano Z (Malvern, UK). UV-vis-NIR absorption spectra were measured by the multifunctional microplate reader (Thermo, USA). Pore size distribution was calculated by the Brunauer-Emmett-Teller method.

\section{Cell Viability and In Vitro Photothermal-Chemo Therapy}

The viability of PVP-Bi $\mathrm{S}_{3}, \mathrm{Bi}_{2} \mathrm{~S}_{3} @ \mathrm{mPS}$, and Tam-Bi $\mathrm{S}_{3} @ \mathrm{mPS}$ NPs as well as DOX was carried out by breast cancer cell line SKBR-3 cells (purchased from the Type Culture Collection of the Chinese Academy of Sciences). Briefly, the cells were seeded onto the substrates at a density of $1 \times 10^{5}$ cells per $\mathrm{cm}^{2}$ and cultured at $37^{\circ} \mathrm{C}$ for $12 \mathrm{~h}$. Then $\mathrm{Bi}_{2} \mathrm{~S}_{3} @ \mathrm{mPS}, \mathrm{Tam}-\mathrm{Bi}_{2} \mathrm{~S}_{3} @ \mathrm{mPS}$, and DOX with a gradient concentration of $0,12.5,25,50$, 100,200 , and $400 \mu \mathrm{g} \mathrm{mL}{ }^{-1}$ were separately added to the plates. After the cells and the NPs or DOX were cocultured for $24 \mathrm{~h}$, the MTT test was performed immediately after treatment.

$\mathrm{Bi}_{2} \mathrm{~S}_{3} @ \mathrm{mPS}$ and Tam-Bi $\mathrm{S}_{3} @ \mathrm{mPS}$ NPs loaded with $25 \mu \mathrm{g} \mathrm{mL} \mathrm{L}^{-1}$ DOX were cultured with SKBR-3 cells for another $6 \mathrm{~h}$. Then the cells were washed with PBS and replaced with fresh medium and irradiated with or without $808 \mathrm{~nm}$ laser $\left(1 \mathrm{~W} \mathrm{~cm}^{-2}\right)$ for $10 \mathrm{~min}$. The standard MTT assay was carried out to determine the cell viabilities relative to the control untreated cells.

\section{Live/Dead Staining}

For viability staining studies, the cells were seeded on 96-well plates at a concentration of 5 $\times 10^{4}$ cells cm ${ }^{-2}$ at $37{ }^{\circ} \mathrm{C}$ with $5 \% \mathrm{CO}_{2}$ for $24 \mathrm{~h} .100 \mu \mathrm{L}$ of NPs $\left(\mathrm{Bi}_{2} \mathrm{~S}_{3} @ \mathrm{mPS}\right.$ and Tam$\mathrm{Bi}_{2} \mathrm{~S}_{3} @ \mathrm{mPS}$ ) with or without $25 \mu \mathrm{g} \mathrm{mL} \mathrm{m}^{-1}$ DOX was added to the plate, then irradiated with or without $808 \mathrm{~nm}$ laser at a density of $1 \mathrm{~W} \mathrm{~cm}^{-2}$ for $10 \mathrm{~min}$. The medium was removed and the adherent cells were subjected to Live/Dead staining following the manufacturer's protocol (Sigma, USA). The cells were then photographed using a fluorescence microscope (Olympus, BX51, Japan). 


\section{In Vitro Tam-Bi $\mathbf{S}_{3} @ m P S$ Targeted}

Fluorescence imaging and flow cytometry were carried out to evaluate the targeting capability of Tam- $\mathrm{Bi}_{2} \mathrm{~S}_{3} @ \mathrm{mPS}$. The FITC labeling of the NPs was done following our previous report. ${ }^{[36]}$ Tam-Bi $2 \mathrm{~S}_{3} @ \mathrm{mPS}-\mathrm{FITC}, \mathrm{Bi}_{2} \mathrm{~S}_{3} @ \mathrm{mPS}-\mathrm{FITC}$, or FITC were cocultured with HER-2 positive SKBR-3 cells or HER-2 negative MCF-7 cells for $24 \mathrm{~h}$. The cells were washed three times with PBS, and then photographed using a fluorescence microscope (Olympus, BX51, Japan). For flow cytometry analysis, the same procedures were carried out, and then the cells were collected and analyzed with a BD FACSCalibur flow cytometer (BD, USA). The results were analyzed by FlowJo 7.6.1.

\section{In Vivo Experiments-Animals}

Female nude mice (6-8 weeks old female Balb/c) were purchased from Medical Experimental Animal Center of Guangdong Province. To establish the tumor model, $5 \times 10^{6}$ SKBR-3 cells were injected in the thymus gland of the mice. All animal studies were approved by Institutional Animal Care and Use Committee (IACUC) of Guangzhou General Hospital of Guangzhou Military Command.

\section{In Vivo Experiments_-In vitro and in vivo $\mathrm{CT}$ imaging}

Different concentrations of Tam-Bi $\mathrm{S}_{3} @ \mathrm{PS}$ and iobitridol were put into 24-well plate under $\mathrm{X}$-ray scanning for $\mathrm{HU}$ value measurement. Tumor-bearing nude mice were i.v. injected with $200 \mu \mathrm{L}$ of $\mathrm{Bi}_{2} \mathrm{~S}_{3} @ \mathrm{mPS}$ and Tam-Bi $\mathrm{S}_{3} @ \mathrm{mPS}$ NPs $\left(10 \mathrm{mg} \mathrm{mL}^{-1}\right)$ separately prior to imaging. After 2, 6, and $24 \mathrm{~h}$, tumor-bearing mice were imaged by the small animal X-ray CT. In vivo CT imaging was performed on small mice X-ray CT (Aloka, Hitachi). Imaging parameters were as follows: scanning resolution $48 \mu \mathrm{m}$, rotation angle $360^{\circ}$, and voltage 80 kv. The CT images were analyzed using amira VGStudio MAX 2.2. The whole mouse body experienced 360 scans, which lasted about 20 min for each mouse.

\section{In Vivo Experiments-In vivo tumor therapy}

When the tumor size reached $0.5 \times 0.5 \mathrm{~cm}^{2}$, the female SKBR-3 tumor-bearing mice were divided into six groups: 1) Tam-Bi $\mathrm{S}_{3} @ \mathrm{mPS} / \mathrm{DOX}+\mathrm{NIR}$; 2) Tam-Bi $2 \mathrm{~S}_{3} @ \mathrm{mPS}+\mathrm{NIR} ; 3$ ) $\left.\mathrm{Bi}_{2} \mathrm{~S}_{3} @ \mathrm{mPS}+\mathrm{NIR} ; 4\right)$ Tam-Bi $\left.\mathrm{S}_{3} @ \mathrm{mPS} / \mathrm{DOX} ; 5\right) \mathrm{DOX}+\mathrm{NIR}$; and 6) Control (NaCl+NIR). After i.v. injection of the above materials, the $808 \mathrm{NIR}$ laser $\left(1 \mathrm{~W} \mathrm{~cm}^{-2}\right)$ was applied to the tumor site for $10 \mathrm{~min}$ at $2 \mathrm{~h}$ postinjection. The photothermal effect was carefully recorded by an infrared (IR) camera. The changes of tumor volumes in all groups were carefully recorded every other day for a period of $14 \mathrm{~d}$. The tumor sizes were measured by a caliper and calculated as follows

$$
V=a b^{2} / 2
$$

where $V\left(\mathrm{~mm}^{3}\right)$ is the volume of the tumor, and $a(\mathrm{~mm})$ and $b(\mathrm{~mm})$ are the tumor length and tumor width, respectively. After $14 \mathrm{~d}$, the mice were anesthetized and killed, the tissues of main organs and tumor tissues were peeled from the mice and fixed in a $4 \%$ formaldehyde solution ( $\mathrm{pH}=7.0$ ). The tissues were processed with paraffin embedding routinely. $3.5 \mu \mathrm{m}$ 
thick sections were then cut and placed on glass slides, followed by staining with H\&E. Finally, the pathological sections were observed at $\times 200$ magnifications using an inverted microscope (BX51, Olympus).

\section{Supplementary Material}

Refer to Web version on PubMed Central for supplementary material.

\section{Acknowledgments}

The authors acknowledge financial support from Program for Innovative Research Team in University of Ministry of Education of China (Grant No. IRT_17R38), the National Key Research and Development Program of China (Grant Nos. 2016YFA0100900, 2017YFF0104504, and 2017YFB0702604), the Key Program of Guangzhou Scientific Research Special Project (Grant No. 201607020009), the National Natural Science Foundation of China (Grant Nos. 51672085, 51673168, and 21620102004), and Fundamental Research Funds for the Central Universities. Y.Z. and C.B.M. also would like to thank the financial support of National Institutes of Health (Grant Nos. CA200504, CA195607, and EB021339) and Department of Defense office of the Congressionally Directed Medical Research Programs (W81XWH-15-1-0180).

\section{References}

1. Dowsett M, Harper-Wynne C, Boeddinghaus I, Salter J, Hills M, Dixon M, Ebbs S, Gui G, Sacks N, Smith I. Cancer Res. 2001; 61:8452. [PubMed: 11731427]

2. a) Jokerst JV, Gambhir SS. Acc Chem Res. 2011; 44:1050. [PubMed: 21919457] b) Bahmani B, Guerrero Y, Bacon D, Kundra V, Vullev VI, Anvari B. Lasers Surg Med. 2014; 46:582. [PubMed: 24961210]

3. a) Akdogan Y, Emrullahoglu M, Tatlidil D, Ucuncu M, Cakan-Akdogan G. Phys Chem Chem Phys. 2016; 18:22531. [PubMed: 27468942] b) Xiao T, Wang Z, Sun X, Song J, Jacobson O, Gang N, Kiesewetter DO, Chen X. Theranostics. 2016; 6:2039. [PubMed: 27698939]

4. Prabhakar U, Maeda H, Jain RK, Sevickmuraca EM, Zamboni W, Farokhzad OC, Barry ST, Gabizon A, Grodzinski P, Blakey DC. Cancer Res. 2013; 73:2412. [PubMed: 23423979]

5. Jiang Y, Wang X, Lv W, Liu X, Zhang H, Zhang M, Li X, Xin H, Xu Q. ACS Appl Mater Interfaces. 2016; 9:211. [PubMed: 27976583]

6. Chen F, Hong H, Goel S, Graves SA, Orbay H, Ehlerding EB, Shi S, Theuer CP, Nickles RJ, Cai W. ACS Nano. 2015; 9:3926. [PubMed: 25843647]

7. Mei L, Zhu G, Qiu L, Wu C, Chen H, Liang H, Cansiz S, Lv Y, Zhang X, Tan W. Nano Res. 2015; 8:3447. [PubMed: 27774139]

8. a) Blackwell KL, Burstein HJ, Storniolo AM, Rugo HS, Sledge G, Aktan G, Ellis C, Florance A, Vukelja S, Bischoff J, Baselga J, O’Shaughnessy J. J Clin Oncol. 2012; 30:2585. [PubMed: 22689807] b) Benezra M, Penate-Medina O, Zanzonico PB, Schaer D, Ow H, Burns A, DeStanchina E, Longo V, Herz E, Iyer S, Wolchok J, Larson SM, Wiesner U, Bradbury MS. J Clin Invest. 2011; 121:2768. [PubMed: 21670497]

9. Lu C, Deng X, Jiang. Chem Commun. 2011; 47:11692.

10. Huo T, Du X, Zhang S, Liu X, Li X. Eur J Radiol. 2010; 73:420. [PubMed: 19261416]

11. Choi WI, Sahu A, Kim YH, Tae G. Ann Biomed Eng. 2012; 40:534. [PubMed: 21887589]

12. Liu Z, Chen X, Zhang X, Gooding JJ, Zhou Y. Adv Healthcare Mater. 2016; 5:1401.

13. Zha Z, Zhang S, Deng Z, Li Y, Li C, Dai Z. Chem Commun. 2013; 49:3455.

14. a) Lusic H, Grinstaff MW. Chem Rev. 2013; 113:1641. [PubMed: 23210836] b) Liu Y, Ai K, Lu L. Acc Chem Res. 2012; 45:1817. [PubMed: 22950890]

15. Bierer DW. Rev Infect Dis. 1990; 12:3.

16. Wei B, Zhang X, Zhang C, Jiang Y, Fu YY, Yu C, Sun SK, Yan XP. ACS Appl Mater Interfaces. 2016; 8:12720. [PubMed: 27144639] 
17. Liu J, Zheng X, Yan L, Zhou L, Tian G, Yin W, Wang L, Liu Y, Hu Z, Gu Z. ACS Nano. 2015; 12:696.

18. a) Zhou SM, Ma DK, Zhang SH, Wang W, Chen W, Huang SM, Yu K. Nanoscale. 2016; 8:1374. [PubMed: 26488908] b) Li B, Ye K, Zhang Y, Qin J, Zou R, Xu K, Huang X, Xiao Z, Zhang W, Lu X, Hu J. Adv Mater. 2015; 27:1339. [PubMed: 25639509]

19. a) Wang Y, Wu Y, Liu Y, Shen J, Lv L, Li L, Yang L, Zeng J, Wang Y, Zhang LW. Adv Funct Mater. 2016; 26:5335.b) Xiao Z, Xu C, Jiang X, Zhang W, Peng Y, Zou R, Huang X, Liu Q, Qin Z, Hu J. Nano Res. 2016; 9:1934.

20. a) Jing L, Wang P, Xiao Z, Wang L, Wang D, Gu Z, Tang J, Guo M, Cao M, Zhou H. ACS Nano. 2016; 10:4587. [PubMed: 27014806] b) Song G, Liang C, Yi X, Zhao Q, Cheng L, Yang K, Liu Z. Adv Mater. 2016; 28:2654.

21. Guerrero-Martinez A, Perez-Juste J, Liz-Marzan LM. Adv Mater. 2010; 22:1182. [PubMed: 20437506]

22. a) Tarn D, Ashley CE, Xue M, Carnes EC, Zink JI, Brinker CJ. Acc Chem Res. 2013; 46:792. [PubMed: 23387478] b) Tang F, Li L, Chen D. Adv Mater. 2012; 24:1504. [PubMed: 22378538]

23. Stöber W, Fink A, Bohn E. Colloid Interface Sci. 1968; 26:62.

24. a) Chou KS, Chen CC. Microporous Mesoporous Mater. 2007; 98:20.b) Feng W, Dong H, Niu L, Wen X, Huo L, Bai G. J Mater Chem A. 2015; 3:1980.

25. a) Choi WI, Lee JH, Kim JY, Heo SU, Jeong YY, Kim YH, Tae G. Nanomedicine. 2015; 11:359. [PubMed: 25262581] b) Zhang L, Su H, Cai J, Cheng D, Ma Y, Zhang J, Zhou C, Liu S, Shi H, Zhang Y. ACS Nano. 2016; 10:10404. [PubMed: 27934087]

26. Bonadonna G, Valagussa P, Zucali R, Salvadori B. Ca-Cancer J Clin. 1995; 45:227. [PubMed: 7600279]

27. Montcourrier P, Mangeat PH, Valembois C, Salazar G, Sahuquet A, Duperray C, Rochefort H. J Cell Sci. 1994; 107:2381. [PubMed: 7844158]

28. Jaque D, Martínez ML, Del RB, Harogonzalez P, Benayas A, Plaza JL, Martín RE, García SJ. Nanoscale. 2014; 6:9494. [PubMed: 25030381]

29. a) Roukos DH. Ann Surg Oncol. 2010; 17:14. [PubMed: 19841980] b) Romond EH, Perez EA, Bryant J, Suman VJ, G C Jr, Davidson NE, Tanchiu E, Martino S, Paik S, Kaufman PA. N Engl J Med. 2005; 353:1673. [PubMed: 16236738]

30. Liu J, Zheng X, Yan L, Zhou L, Tian G, Yin W, Wang L, Liu Y, Hu Z, Gu Z, Chen C, Zhao Y. ACS Nano. 2015; 9:696. [PubMed: 25561009]

31. a) Zhang Y, Zhang H, Wang Y, Wu H, Zeng B, Zhang Y, Tian Q, Yang S. J Mater Chem B. 2017; 5:1846.b) Zhang XD, Chen J, Min Y, Park GB, Shen X, Song SS, Sun YM, Wang H, Long W, Xie J. Adv Funct Mater. 2013; 24:1718.

32. Dou R, Du Z, Bao T, Dong X, Zheng X, Yu M, Yin W, Dong B, Yan L, Gu Z. Nanoscale. 2016; 8:11531. [PubMed: 27203525]

33. Mitragotri S, Yoo JW. Arch Pharmacal Res. 2011; 34:1887.

34. Folberg R, Pe'Er J, Gruman LM, Woolson RF, Jeng G, Montague PR, Moninger TO, Yi H, Moore KC. Hum Pathol. 1992; 23:1298. [PubMed: 1427757]

35. Yu SS, Lau CM, Thomas SN, Jerome WG, Maron DJ, Dickerson JH, Hubbell JA, Giorgio TD. Int J Nanomed. 2012; 7:799.

36. Li L, Yang X, Hu X, Lu Y, Wang L, Peng M, Xia H, Yin Q, Zhang Y, Han G. J Mater Chem B. 2017; 5:6470. 


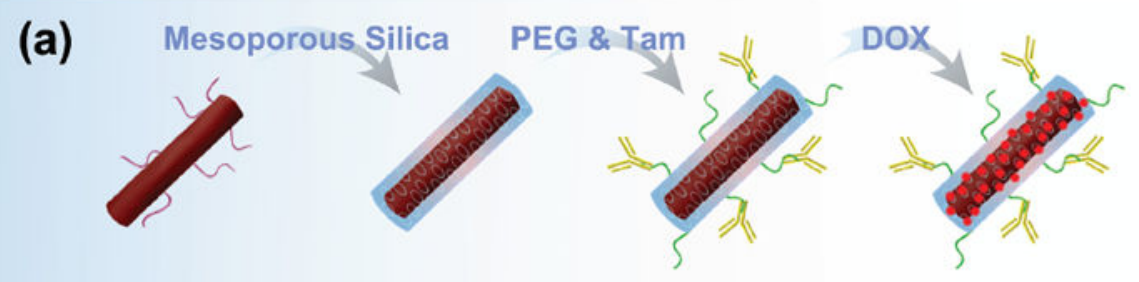

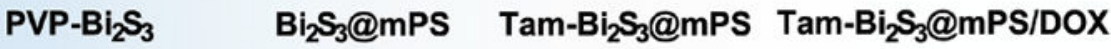
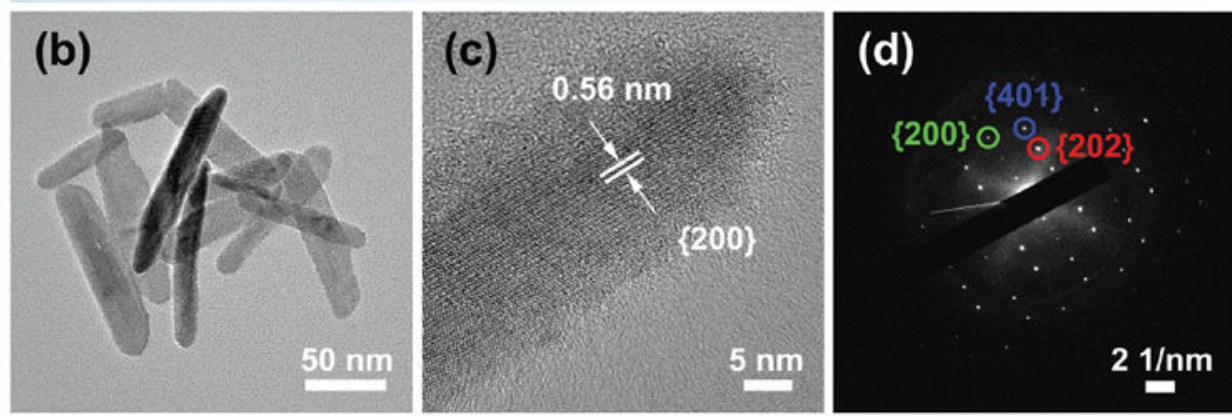

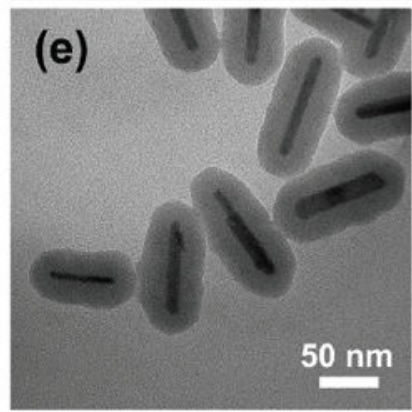

(g)

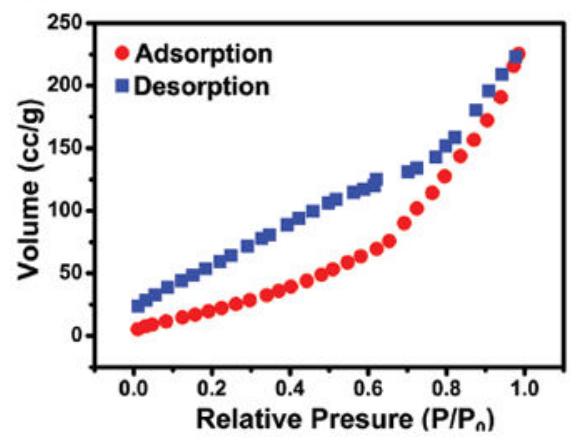

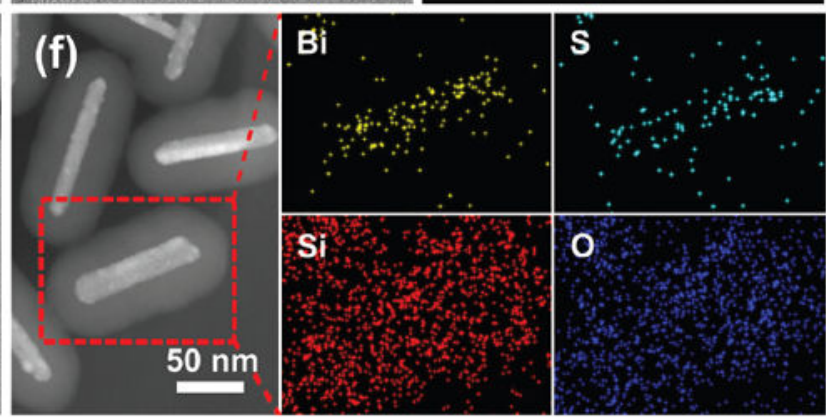

(h)

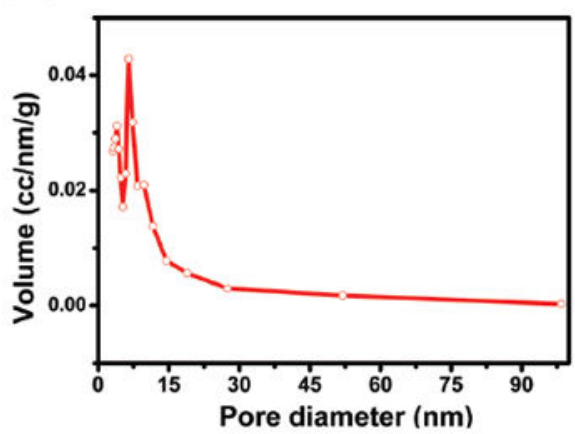

Figure 1.

Synthesis and characterization of $\mathrm{Bi}_{2} \mathrm{~S}_{3}$ nanoparticles. a) Synthetic procedure of Tam$\mathrm{Bi}_{2} \mathrm{~S}_{3} @ \mathrm{mPS}$ with a high targeting activity. First PVPassisted $\mathrm{Bi}_{2} \mathrm{~S}_{3}\left(\mathrm{PVP}-\mathrm{Bi}_{2} \mathrm{~S}_{3}\right)$ NPs were synthesized, followed by the deposition of mPS coating to form $\mathrm{Bi}_{2} \mathrm{~S}_{3} @ \mathrm{mPS}$ NPs. Then a cancer-targeting antibody (Tam) was conjugated to $\mathrm{Bi}_{2} \mathrm{~S}_{3} @$ mPS NPs through a PEG linker to form Tam-Bi $\mathrm{S}_{3} @ \mathrm{mPS}$ NPs. Finally an anticancer drug DOX was loaded on the resultant NPs to form Tam- $\mathrm{Bi}_{2} \mathrm{~S}_{3} @ \mathrm{mPS} / \mathrm{DOX}$. b) TEM image of the hydrophilic PVP-Bi $\mathrm{S}_{3}$ NPs. c) HRTEM image and d) SAED pattern of an individual PVP-Bi $2 \mathrm{~S}_{3}$ NP. e) TEM image of the $\mathrm{Bi}_{2} \mathrm{~S}_{3} @$ mPS NPs. f) HAADF-STEM image of $\mathrm{Bi}_{2} \mathrm{~S}_{3} @$ mPS NPs and the elemental mapping 
of $\mathrm{Si}, \mathrm{O}, \mathrm{S}$, and $\mathrm{Bi}$ from the highlighted area. $\mathrm{g}$ ) Nitrogen adsorption/desorption isotherms of $\mathrm{Bi}_{2} \mathrm{~S}_{3} @ \mathrm{mPS}$ NPs. h) Pore size distributions of $\mathrm{Bi}_{2} \mathrm{~S}_{3} @ \mathrm{mPS}$ NPs. 

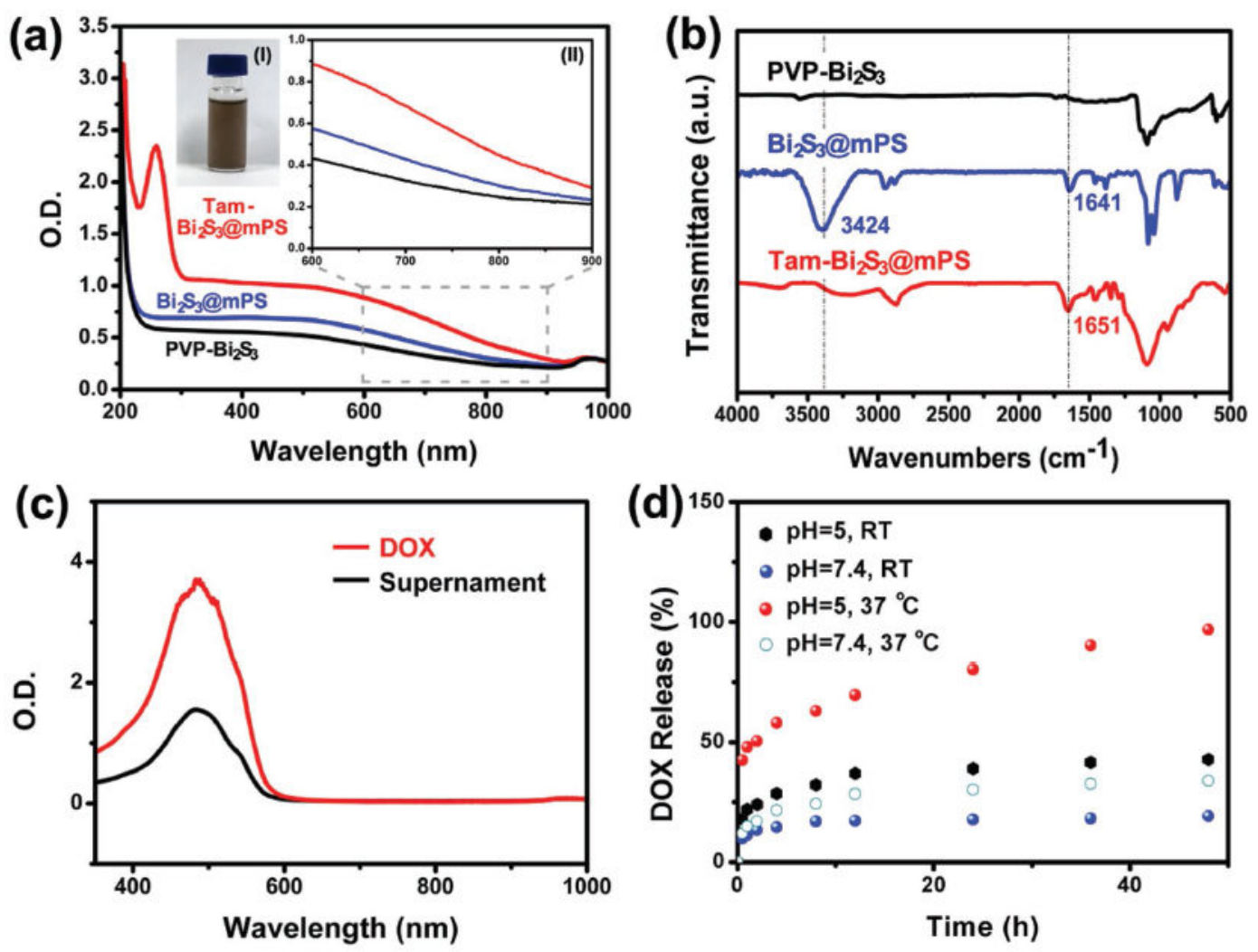

Figure 2.

Spectroscopic characterization as well as drug loading and release of different nanoparticles. a) UV-vis spectra of PVP- $\mathrm{Bi}_{2} \mathrm{~S}_{3}, \mathrm{Bi}_{2} \mathrm{~S}_{3} @ \mathrm{mPS}$ and Tam- $\mathrm{Bi}_{2} \mathrm{~S}_{3} @ \mathrm{mPS}$. Inset: I) Image of Tam-Bi ${ }_{2} \mathrm{~S}_{3} @ \mathrm{mPS}$ aqueous solution $\left(200 \mu \mathrm{g} \mathrm{mL} \mathrm{m}^{-1}\right)$; II) magnified region (600-900 nm) of the UV-vis spectra of PVP-Bi $\mathrm{S}_{3}, \mathrm{Bi}_{2} \mathrm{~S}_{3} @ \mathrm{mPS}$ and Tam- $\mathrm{Bi}_{2} \mathrm{~S}_{3} @ \mathrm{mPS}$. b) FTIR spectra of PVP-Bi ${ }_{2} \mathrm{~S}_{3}, \mathrm{Bi}_{2} \mathrm{~S}_{3} @ \mathrm{mPS}$, and Tam-Bi $2 \mathrm{~S}_{3} @$ mPS. c) Drug-loading efficiency of DOX on $\mathrm{Bi}_{2} \mathrm{~S}_{3} @ \mathrm{mPS}$. A DOX solution was added to $\mathrm{Bi}_{2} \mathrm{~S}_{3} @ \mathrm{mPS}$ solution. After drug loading, the mixture was centrifuged. The red and black curve represented the absorption spectrum of the original DOX solution and the supernatant, respectively, indicating the successful drug loading. d) Drug release from $\mathrm{Bi}_{2} \mathrm{~S}_{3} @ \mathrm{mPS}$ at pH 5 and 7.4 at room temperature and $37{ }^{\circ} \mathrm{C}$. 
(a)

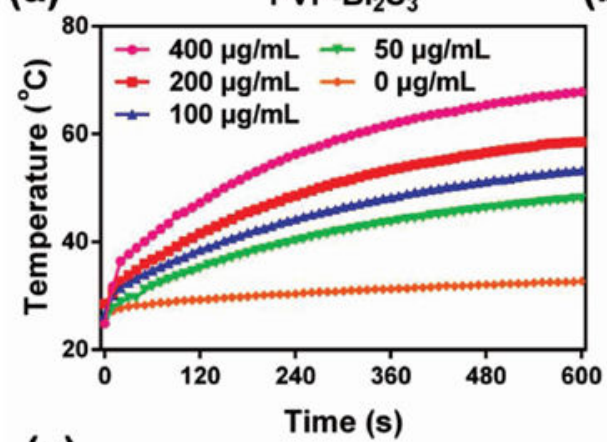

(c)

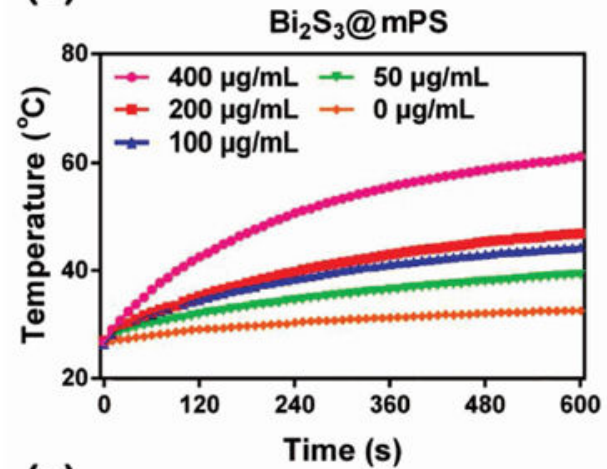

(e)

$0 \min 2 \min 4 \min 6 \min 8 \min 10 \min$

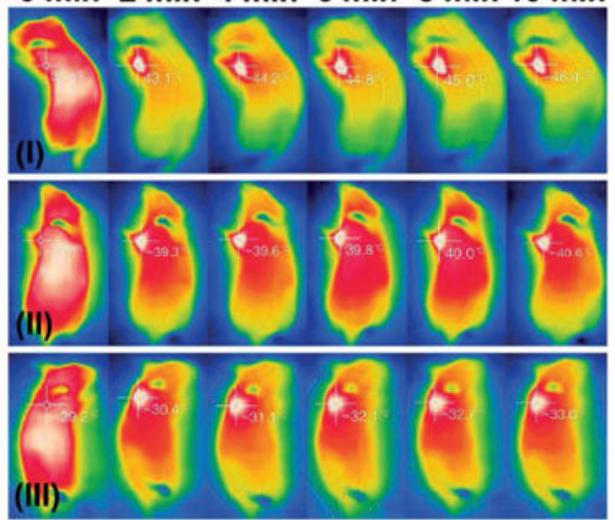

(b)

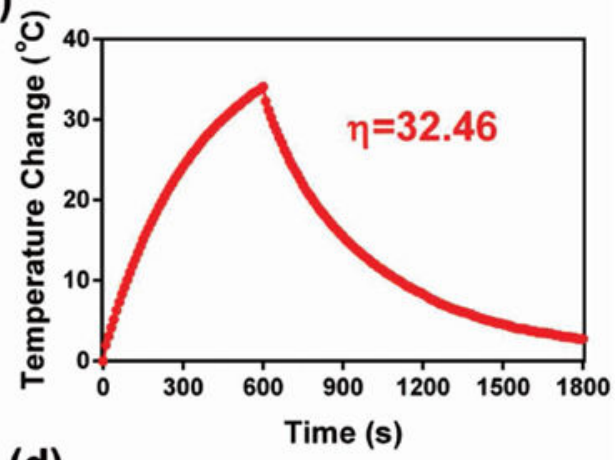

(d)

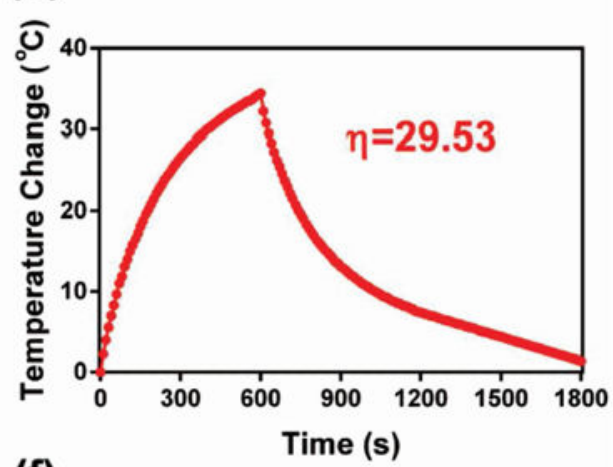

(f)
Time (s)

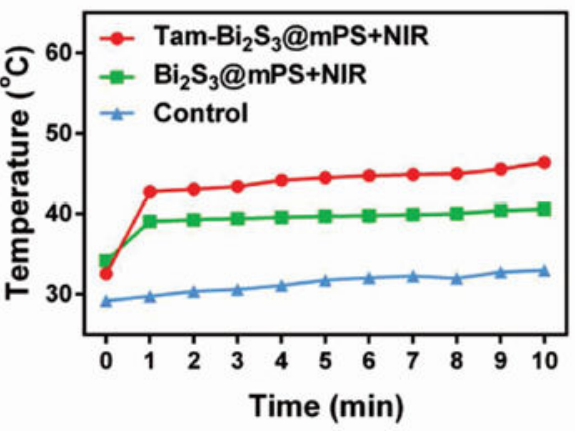

Figure 3.

Photothermal properties of nanoparticles in vitro and in vivo. Quantitative temperature change of a) PVP-Bi ${ }_{2} \mathrm{~S}_{3} \mathrm{c}$ ) and $\mathrm{Bi}_{2} \mathrm{~S}_{3} @ \mathrm{mPS}$ with different concentrations under $1 \mathrm{~W} \mathrm{~cm}^{-2}$ $808 \mathrm{~nm}$ laser irradiation. Heating/cooling experiment of b) PVP-Bi ${ }_{2} \mathrm{~S}_{3}$ and c) $\mathrm{Bi}_{2} \mathrm{~S}_{3} @ \mathrm{mPS}$ nanoparticles solution $\left(400 \mu \mathrm{g} \mathrm{mL}^{-1}\right)$ under $1 \mathrm{~W} \mathrm{~cm}^{-2} 808 \mathrm{~nm}$ laser irradiation. The laser was on from 0 to $600 \mathrm{~s}$ and then off from 600 to $1800 \mathrm{~s}$. The PTC efficiencies were indicated as $\eta$. e) IR images of the animals captured every 2 min (from left to right) showing the temperature change at tumor sites under $1 \mathrm{~W} \mathrm{~cm}^{-2} 808 \mathrm{~nm}$ laser irradiation. The light was only applied to the tumors during the measurements after i.v. injection of different samples. I, II, and III represent the Tam- $\mathrm{Bi}_{2} \mathrm{~S}_{3} @ \mathrm{mPS}, \mathrm{Bi}_{2} \mathrm{~S}_{3} @ \mathrm{mPS}$, and control (no particles) group, respectively. f) Quantitative temperature change at the tumor site in the Tam- $\mathrm{Bi}_{2} \mathrm{~S}_{3} @ \mathrm{mPS}$, 
$\mathrm{Bi}_{2} \mathrm{~S}_{3} @ \mathrm{mPS}$, and control group derived from IR camera measurements shown in panel (e). These data confirm that Tam- $\mathrm{Bi}_{2} \mathrm{~S}_{3} @$ mPS NPs favor the accumulation of NPs at the tumor sites due to their tumor-targeting capability. 
(a)

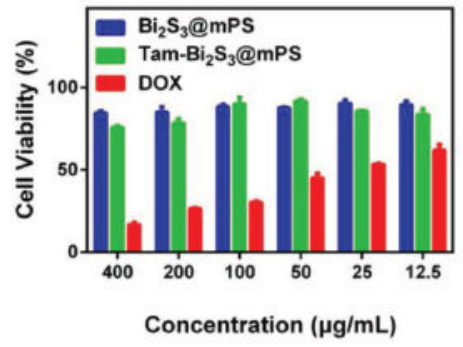

(d)
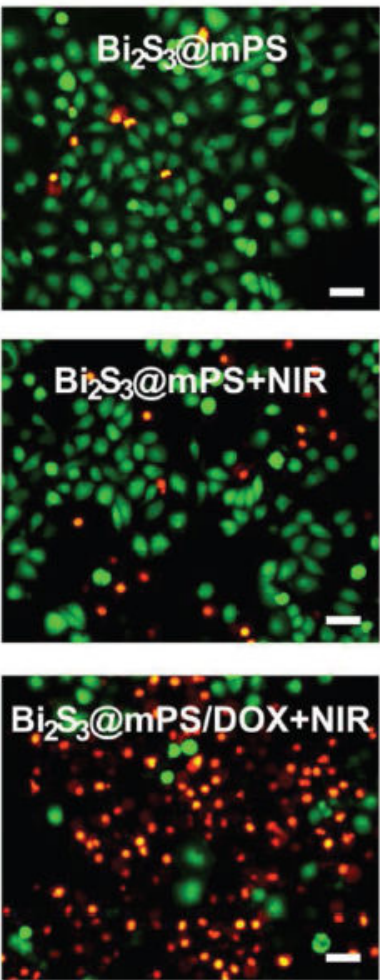

(b)
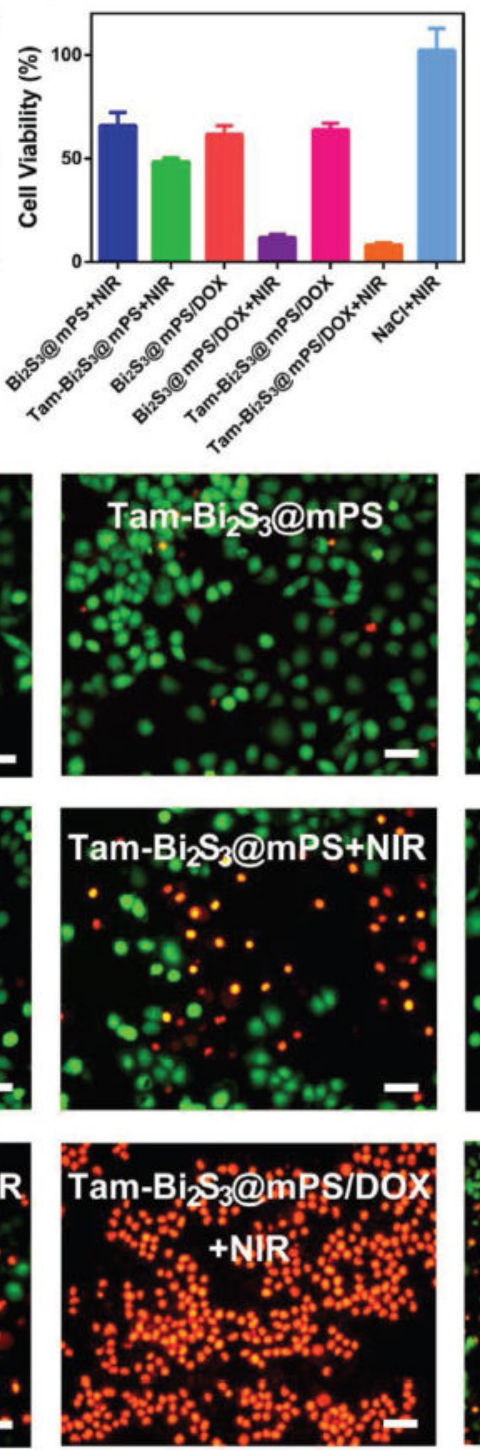

(c)
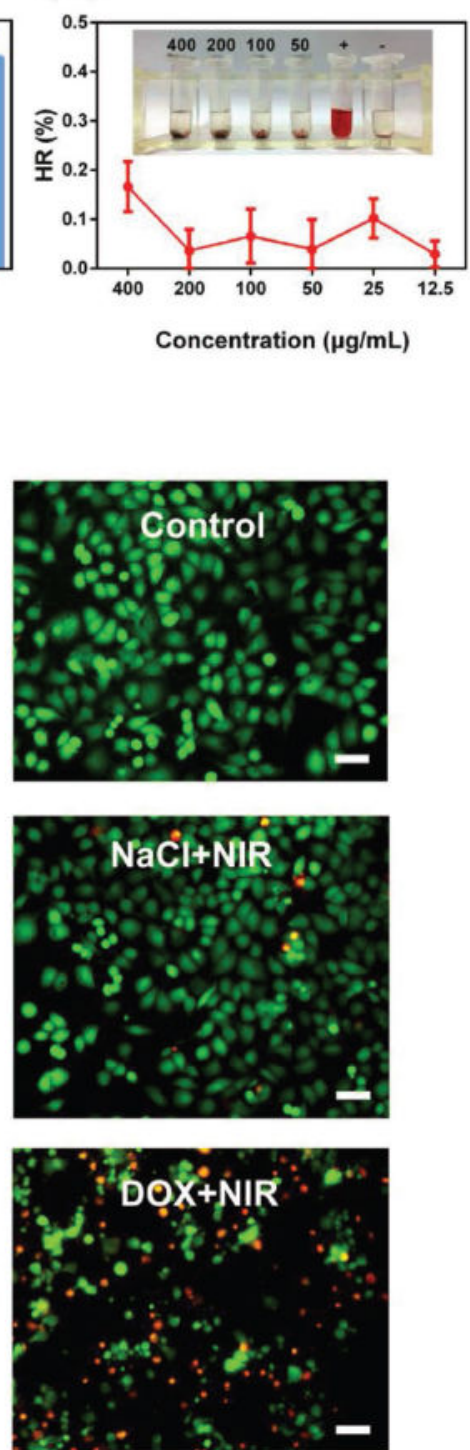

Figure 4.

In vitro cancer therapy by nanoparticles. a) Cell viability of SKBR-3 cells after being cultured with different concentrations of $\mathrm{Bi}_{2} \mathrm{~S}_{3} @ \mathrm{mPS}, \mathrm{Tam}-\mathrm{Bi}_{2} \mathrm{~S}_{3} @ \mathrm{mPS}$, and DOX for $24 \mathrm{~h}$. b) Cancer cell killing effect of $\mathrm{Bi}_{2} \mathrm{~S}_{3} @ \mathrm{mPS}$, Tam-Bi $\mathrm{i}_{2} \mathrm{~S}_{3} @ \mathrm{mPS}, \mathrm{Bi}_{2} \mathrm{~S}_{3} @ \mathrm{mPS} / \mathrm{DOX}$, and Tam-Bi $\mathrm{S}_{2} @ \mathrm{mPS} / \mathrm{DOX}$ under $808 \mathrm{~nm}$ laser irradiation for $10 \mathrm{~min}$. c) The hemolytic ratio of Tam-Bi $\mathrm{S}_{3} @ \mathrm{mPS}$ with different concentrations. NPs with different concentrations, purified water $(+)$, and saline (-) are added to the centrifuge tubes to test the hemolytic properties of the NPs. The inset shows the picture of the centrifuge tubes after centrifugation. The slight red color at the bottom of the tubes in the NP group indicate the presence of few human red blood cells in the precipitates, suggesting the excellent blood compatibility of the NPs. d) Fluorescence micrographs of live/dead dye-stained SKBR-3 cells after cocultured with different nanoparticle groups with or without $808 \mathrm{~nm}$ laser irradiation $\left(1 \mathrm{~W} \mathrm{~cm}^{-2}\right)$, showing 
that Tam- $\mathrm{Bi}_{2} \mathrm{~S}_{3} @ \mathrm{mPS} / \mathrm{DOX}+\mathrm{NIR}$ group has the best photothermal killing effect on the cancer cells. Scale bar $=50 \mu \mathrm{m}$. 
(a)
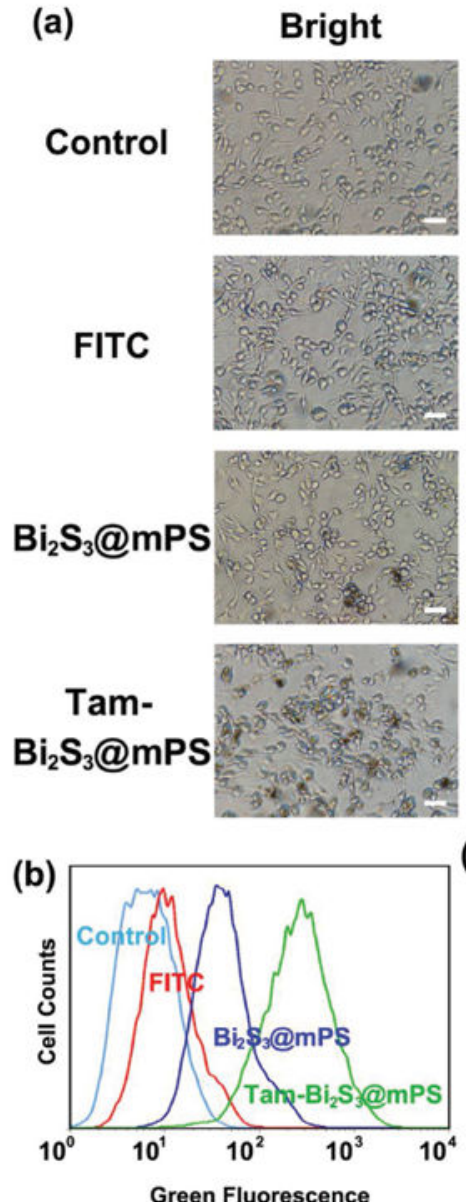

FITC
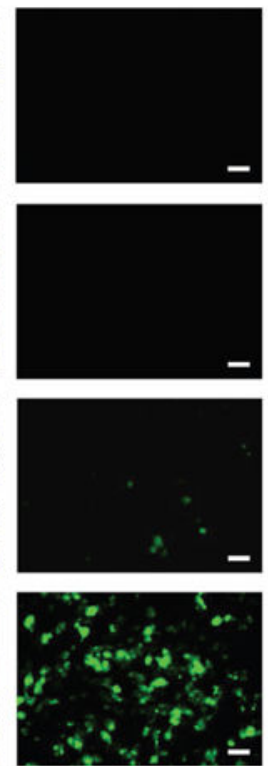

(c)

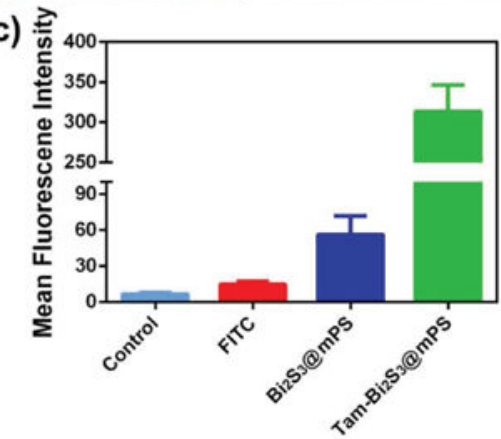

Figure 5.

In vitro assay verifying the internalization of nanoparticles by SKBR-3 cancer cells. a) Fluorescence images of SKBR-3 cells cocultured with free FITC as well as FITC-labeled $\mathrm{Bi}_{2} \mathrm{~S}_{3} @ \mathrm{mPS}$ and Tam- $\mathrm{Bi}_{2} \mathrm{~S}_{3} @ \mathrm{mPS}$. b) Flow cytometry analysis of SKBR-3 cells stained by the FITC-labeled $\mathrm{Bi}_{2} \mathrm{~S}_{3} @ \mathrm{mPS}$ and Tam- $\mathrm{Bi}_{2} \mathrm{~S}_{3} @ \mathrm{mPS}$. c) Quantitative analysis of fluorescence intensity of the SKBR-3 cells stained by free FITC as well as FITC-labeled $\mathrm{Bi}_{2} \mathrm{~S}_{3} @ \mathrm{mPS}$ and Tam-Bi $\mathrm{S}_{3} @ \mathrm{mPS}$ Scale bar=50 $\mu \mathrm{m}$. 
(a)

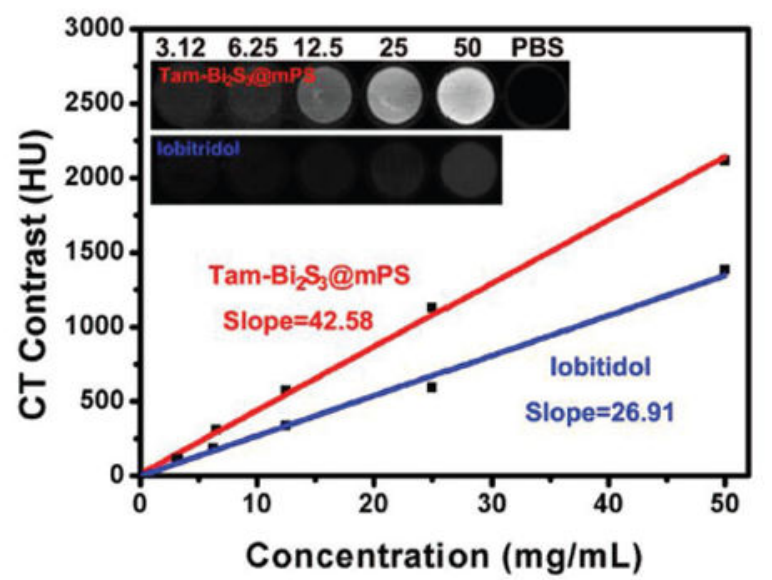

(b)
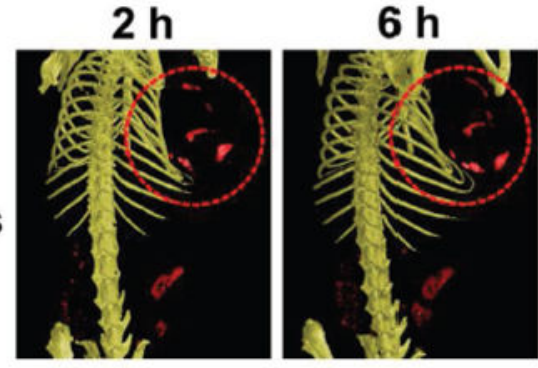
$24 \mathrm{~h}$

Tam$\mathrm{Bi}_{2} \mathrm{~S}_{3} @ \mathrm{mPS}$
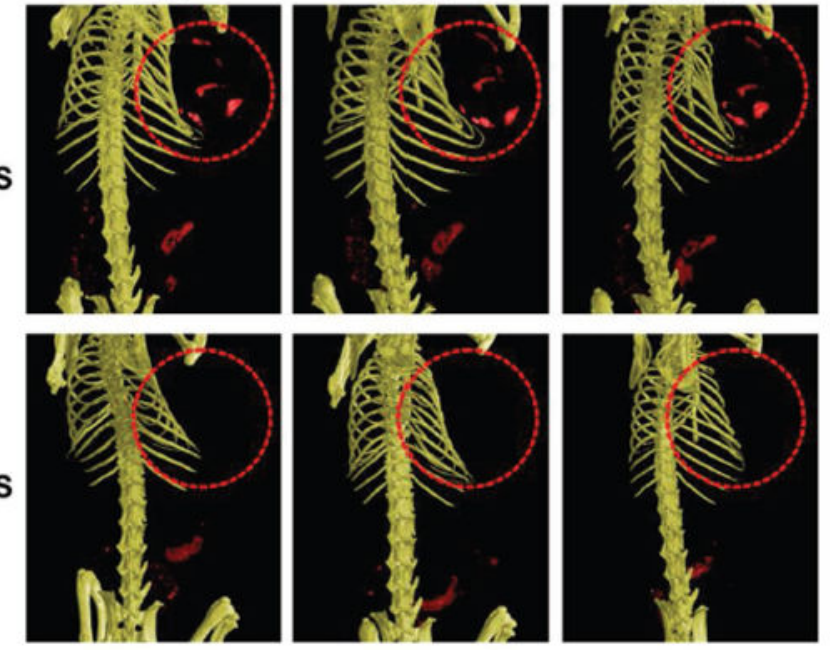

$\mathrm{Bi}_{2} \mathrm{~S}_{3} @ \mathrm{mPS}$

Figure 6.

In vitro and in vivo $\mathrm{CT}$ imaging enhanced by $\mathrm{Tam}-\mathrm{Bi}_{2} \mathrm{~S}_{3} @ \mathrm{mPS}$ nanoparticles. a) CT value $(\mathrm{HU})$ of Tam- $\mathrm{Bi}_{2} \mathrm{~S}_{3} @ \mathrm{mPS}$ and iobitridol with different concentrations under $80 \mathrm{kV}$. Inset: In vitro CT images of Tam- $\mathrm{Bi}_{2} \mathrm{~S}_{3} @ \mathrm{mPS}$ and iobitridol suspensions with different concentrations. b) In vivo CT images of SKBR-3 bearing nude mice recorded at 2, 6, and 24 $\mathrm{h}$ after intravenous injection of $200 \mu \mathrm{L}$ Tam-Bi $\mathrm{S}_{3} @ \mathrm{mPS}$ and $\mathrm{Bi}_{2} \mathrm{~S}_{3} @ \mathrm{PS}$ solution with a concentration of $10 \mathrm{mg} \mathrm{mL}^{-1}$. The tumor site is highlighted by a red circle. This data suggests that tumor targeting of Tam- $\mathrm{Bi}_{2} \mathrm{~S}_{3} @ \mathrm{mPS}$ resulted in the accumulation of the NPs at the tumor sites, enabling the detection of tumors by $\mathrm{CT}$. 
(a)

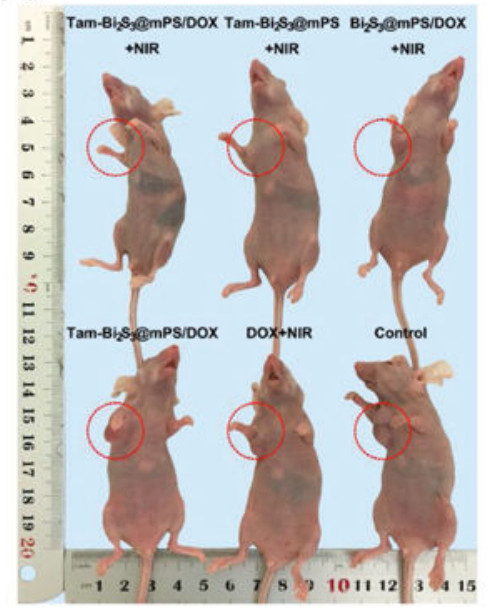

(c)

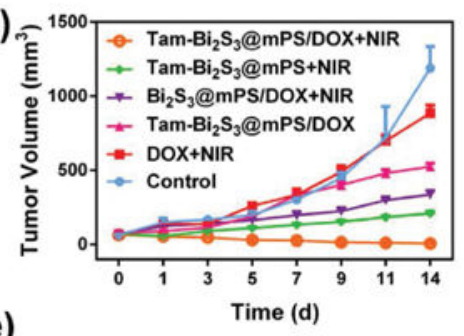

(b)
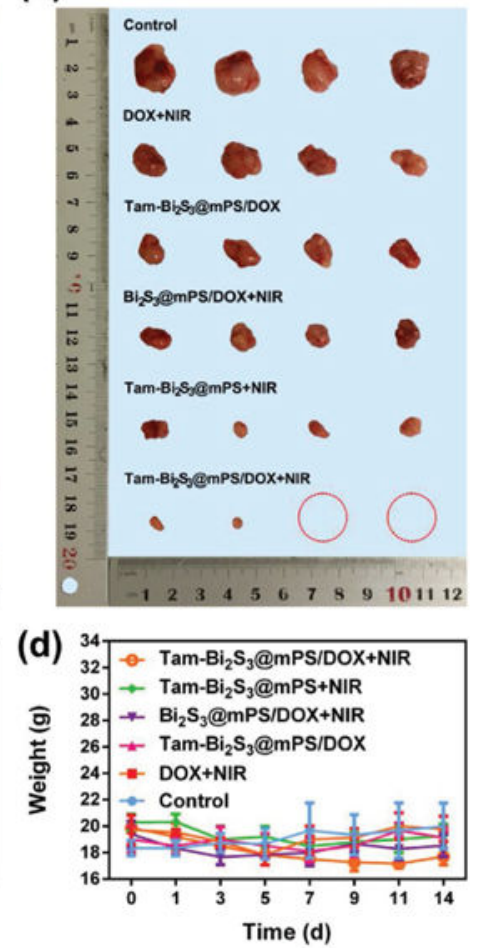

(e)

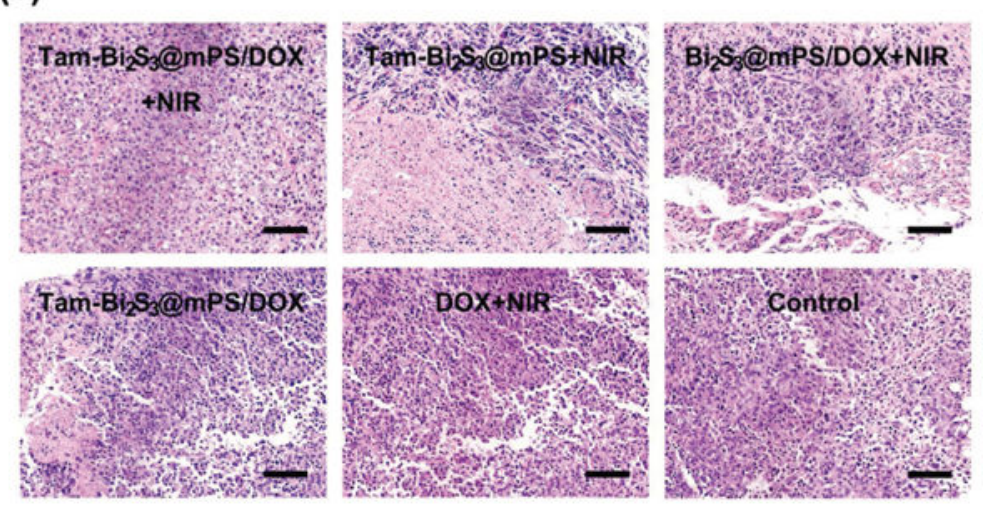

Figure 7.

In vivo cancer therapy by different nanoparticles, showing that Tam-Bi $\mathrm{S}_{3} @ \mathrm{mPS} / \mathrm{DOX}+\mathrm{NIR}$ group has the best synergistic therapy performance. a) Representative photos of SKBR-3 bearing nude mice in different treatment groups $14 \mathrm{~d}$ after treatment. b) Representative photos tumors collected from different treatment groups of mice $14 \mathrm{~d}$ after treatment. c) Tumor volume growth curves of different treatment groups of mice during a period of $14 \mathrm{~d}$. d) Dynamic body change of different treatment groups of mice during a period of $14 \mathrm{~d}$. e) $\mathrm{H} \& \mathrm{E}$ staining of tumor tissues harvested from the different mice groups. Scale bar $=200 \mu \mathrm{m}$. 


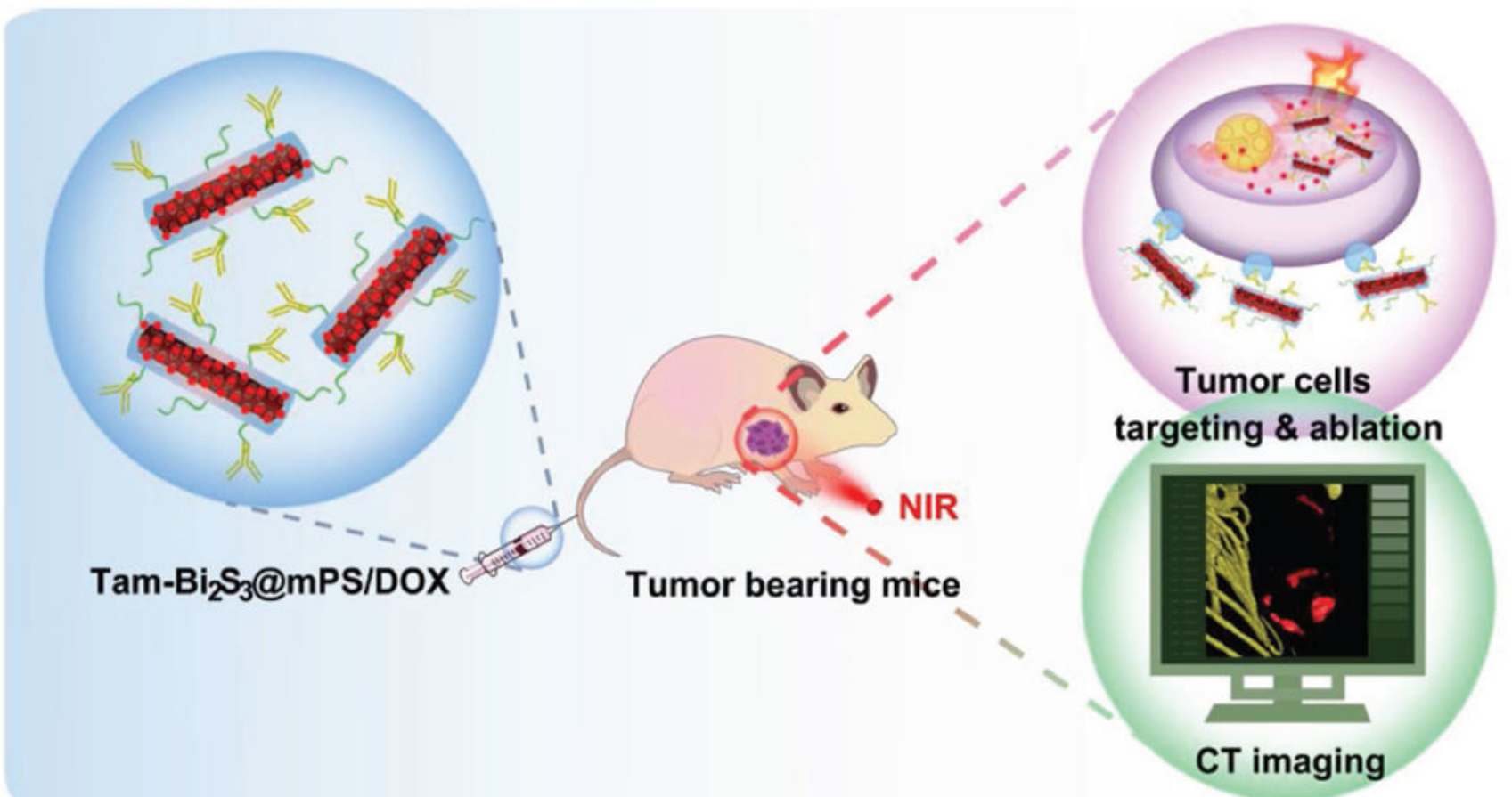

Scheme 1.

Schematic illustration of the targeted Tam- $\mathrm{Bi}_{2} \mathrm{~S}_{3} @ \mathrm{mPS}$ theranostic nanoplatform. 